Illinois State University

ISU ReD: Research and eData

Theses and Dissertations

6-11-2014

\title{
Working Class Women, Body Image Resiliency, and Media Depictions of the Female Body
}

\author{
Emily K. Healy \\ Illinois State University, emily.k.healy@gmail.com
}

Follow this and additional works at: https://ir.library.illinoisstate.edu/etd

Part of the Sociology Commons

\section{Recommended Citation}

Healy, Emily K., "Working Class Women, Body Image Resiliency, and Media Depictions of the Female Body" (2014). Theses and Dissertations. 204.

https://ir.library.illinoisstate.edu/etd/204

This Thesis is brought to you for free and open access by ISU ReD: Research and eData. It has been accepted for inclusion in Theses and Dissertations by an authorized administrator of ISU ReD: Research and eData. For more information, please contact ISUReD@ilstu.edu. 


\title{
WORKING CLASS WOMEN, BODY IMAGE RESILIENCY, AND MEDIA DEPICTIONS OF THE FEMALE BODY
}

\author{
Emily K. Healy
}

83 Pages

August 2014

This study qualitatively examines the body image experiences of nine working class women. It explores the intersections of class, body image, media depictions of the female body, and body image resiliency. 
WORKING CLASS WOMEN, BODY IMAGE RESILIENCY, AND

MEDIA DEPICTIONS OF THE FEMALE BODY

EMILY K. HEALY

A Thesis Submitted in Partial

Fulfillment of the Requirements

for the Degree of

MASTER OF SCIENCE

Department of Sociology and Anthropology

ILLINOIS STATE UNIVERSITY

2014 
(C) 2014 Emily K. Healy 
WORKING CLASS WOMEN, BODY IMAGE RESILIENCY, AND MEDIA DEPICTIONS OF THE FEMALE BODY

EMILY K. HEALY

COMMITTEE MEMBERS:

Diane L. Bjorklund, Chair

David K. Brown

Frank D. Beck 


\section{ACKNOWLEDGMENTS}

I would like to thank my thesis chair, Dr. Diane Bjorklund, for her gracious supervision and guidance of my thesis and, in particular, her careful attention to detail, thought-provoking feedback, and overall support. I would also like to thank Dr. David Brown for his consideration in providing direction and indispensable commentary throughout the research and writing process. In addition, I would like to thank Dr. Beck for his encouragement as a thesis committee member. Furthermore, I would like to warmly thank the women who participated in this research, giving me the gift of their time, their opinions, sharing their stories with me, and without whom I would not have had the opportunity to see this project to fruition. I would also like to thank Barbara Hemme, the sociology instructor who introduced me to this discipline, as well as my fellow graduate cohort members, the knowledgeable and supportive professors in the Sociology Department at Illinois State University, and the close friends who believed in me (and who gave me words of wisdom, inspired me with hope, reassured me, and most importantly, put up with me) throughout this process. I would like to dedicate a heartfelt thank you to my cat, Chicago Bodhisattva Healy, who always reminded me to keep things in perspective. I would like to thank my grandparents, Anne and Martin Healy, and Gloria and Gerald Hofman, as well as my extended family members, whom I know are immeasurably proud of my accomplishments. I would like to thank my little brother, Luke, for being who he is, making the choices he has made in good faith throughout his adulthood, and for living in pursuit of discovering his dreams in life - a task very few of 
us could do with such authenticity. Finally, I would like to thank my incredible parents, Mark and Kim Healy, for pushing me to succeed, for providing me with the love and opportunities that have allowed me to accomplish all that I have been able to, and for daring to hold me to higher aspirations than I often held myself. I cannot possibly express the love and gratitude that I have for them. Without the encouragement, reassurance, and sheer optimism from these individuals who believed that I could succeed, I could not have done this.

E. K. H. 


\section{CONTENTS}

Page

ACKNOWLEDGMENTS $\quad$ i

CONTENTS iii

CHAPTER

I. WORKING CLASS WOMEN, BODY IMAGE RESILIENCY, AND MEDIA DEPICTIONS OF THE FEMALE BODY 1

INTRODUCTION

LITERATURE REVIEW 3

Body Image Dissatisfaction 3

Impacts of the Media on Body Image 4

Impacts of Social Class Position on Body Image 8

Body Image and Strategies of Resilience $\quad 11$

Defining the Working Class 13

Gaps in the Literature 16

RESEARCH DESIGN AND METHODS 19

Sample and Data Collection Methods $\quad 19$

Data Management and Analysis 23

$\begin{array}{ll}\text { FINDINGS } & 24\end{array}$

Working Class Women's Interpretations of Social Class and Body Image 25

Working Class Women's Perceptions of the Effects of the Media on Body Image 28

Educational attainment $\quad 29$

Working Class Women's Understandings of Their Own Bodies 35

Significance of age and experience on body image perception 37

The effects of childbearing on body image perception 40 
Strategies of Body Image Resiliency 44

Body image impacts from family members $\quad 45$

Providing positive support to others 48

Positive reinforcement from a partner or significant other $\quad 50$

Practicing femininity $\quad 54$

Positive self-reinforcement 56

$\begin{array}{ll}\text { Cultivating realistic goals and expectations } & 57\end{array}$

Disregarding thin ideal media imagery and media messages about beauty 61

DISCUSSION 63

II. AN EXAMINATION OF RESEARCH INTERESTS, METHODOLOGICAL ISSUES, AND ETHICAL CONCERNS 69

RESEARCH INTERESTS $\quad 69$

METHODOLOGICAL ISSUES $\quad 70$

ETHICAL CONCERNS $\quad 72$

$\begin{array}{ll}\text { REFERENCES } & 74\end{array}$

$\begin{array}{ll}\text { APPENDIX: Interview Guide } & 79\end{array}$ 


\section{CHAPTER I}

\section{WORKING CLASS WOMEN, BODY IMAGE RESILIENCY, AND MEDIA DEPICTIONS OF THE FEMALE BODY}

\section{INTRODUCTION}

This study qualitatively explored the perspectives that working class women have on their bodies, body image, and experiences in regard to thin ideal media depictions of the female body. Previous research has found that the media generally depict a thin body type that may be unattainable for many women whose bodies do not inherently resemble this ideal. Research in this subject area has also found that this kind of imagery can be detrimental to female consumers who are exposed to it because it often does not depict a diverse range of body types. In the media, there is often a rigid adherence to the thin ideal, and the media also act as a cultural conduit through which socially-determined standards for feminine beauty are disseminated. Due to the prevalence of the media through access points like television, film, advertisements, celebrity culture, and the like, these images have transcended class boundaries. The issue of class in relation to body image is of interest to pursue, particularly to the sociological community, because social researchers tend to attribute considerable importance to social class placement as well as individual attitudes, which may lead to the belief that these variables would have an important bearing in the case of working class women. Findings from this study, however, suggest that social class is not an important factor in how working class women 
approach the interpretation of their bodies, particularly in relation to the thin ideal media imagery they have been exposed to. This study utilized in-depth interviews to investigate whether working class women draw upon class-based repertoires in response to these media images, and whether class position informs the resultant thoughts, feelings, and actions they undertake, in particular, what resistance or resilience strategies they elect to establish, maintain, or ensure a more positive body image overall.

This study found that the issue of social class placement in relation to thin ideal media imagery of the female body and the resultant cultural messages regarding standards for feminine beauty is not a concept that working class women speak to in terms of framing their own interpretations of their bodies. This study found that much like previous studies, which include middle-class and college-educated women, working class women express an awareness of the contradictory messages of beauty and standards for feminine bodily appearance promulgated by the media. Of the working class women included in this study, participants reported that age and life experiences (such as marriage and having children) emerged as reasons for not adhering to the mediapromulgated thin ideal body, which resonate with the findings from previous studies of middle class women who reported similar interpretations of these experiences. The participants furthermore detailed a variety of sociocultural influences that impacted their body image resiliency, and indicated that family support, spousal or partner support, peer-based reinforcement, and self-reinforcement were integral factors to cultivating and maintaining a positive overall body image outlook, echoing the findings from studies of middle class women who also enact these strategies of resistance in response to thin ideal media imagery. 


\section{LITERATURE REVIEW}

The subject of body image is a multifaceted field of research, one that encompasses a variety of socioeconomic indicators as well as factors such as age, gender, and other variables for analysis. In conjunction with my research, I investigated previous research regarding body image, the media, and social class. This prior research included the subject area of body image dissatisfaction, in addition to the impacts of the media on body image, as well as the impacts of social class position on body image. Prior literature also draws upon the subject matter of strategies of resilience and their relevant links to the subject area of body image. Because the women in this study would be considered working class by many sociologists, it is also important to discuss how to define the working class.

\section{Body Image Dissatisfaction}

Studies have found that many women in Western countries experience discontent with their bodies, a concept referred to as body image dissatisfaction. A major topic in body image research has been uncovering the various factors that contribute to this dissatisfaction. One model for understanding this issue is the tripartite influence model, which proposes that a combination of influences from family members, peer groups, and the media can affect how an individual woman interprets and experiences her body (Shroff and Thompson 2005). Women who experience the negative effects of these various sociocultural forces may experience body image dissatisfaction by internalizing the messages they receive about societal standards for beauty and bodily appearance, and they may also negatively compare and evaluate themselves against thin ideal images they see in the media (Shroff and Thompson 2005:18). It is interesting to note that the 
sociocultural messages equating beauty with a slender body type tend to affect women more than men, particularly in the way one is regarded as attractive by members of the opposite sex. Women "realize these pressures more than men do since men have been shown to emphasize physical attraction to a greater degree than do women when choosing a partner" (McGrath et al. 2010).

Cultural pressures and expectations can also be mediated through the family. Laura Hensley Choate (2005) found that there are various family characteristics that can contribute to a negative body image. These factors include "negative family attitudes and behaviors regarding food, including parental modeling of the importance of thinness, weight, and shape issues," "critical comments about an individual's weight, shape, or eating behaviors," as well as teasing by family members, a history of overweight in the family, and "perceived parental pressure to be slender and to control weight and shape" (p. 321). Additionally, women may receive sociocultural messages from their peer groups. Researchers have commented that the impact of peer influence is particularly pronounced during a woman's formative years and adolescence (Choate 2005; McGrath et al. 2010). Female friendship groups often "share comparable levels of dieting behavior, drive for thinness, and overall body image concerns" (Choate 2005:321). In addition to the sources of family and peer influences that can impact body image, the media is an additional component of the tripartite model that can affect women and their evaluations of themselves and their bodies.

\section{Impacts of the Media on Body Image}

The idealized female body as disseminated in various forms by the mass media places pressure on women who consume these media to conform to the rigidly-defined 
slender female forms that they see, though there are great variations in the way women's bodies actually look (Wykes and Gunter 2005). The ideal of female beauty that is most widely presented by the media is thinner and taller than the average woman (Spitzer et al. 1999). One study has found that modern fashion models are thinner than 98 percent of U.S. women (Smolak 2004). Studies of the number of hours of television watched have found an increased preference for the thin-ideal body shape in surveys of preteen girls, teenage girls, and young women who watch more television (Wykes and Gunter 2005). Such imagery reflects some of the values of the culture that creates these depictions and disseminates social implications to women: that beauty in Western culture is confined to women who emulate the thin ideal, with little deviation from this standard. Some of the practices that women undertake may be enacted to resist the images and messages they encounter.

Many U.S. households contain television sets, and this indicates that individuals across a range of social classes have exposure to similar media. "Television, with its constant flow, enormous reach, and vast space-filling needs, has from its initial boom provided the most significant new outlet for image creation" (Gamson 1994:43). Glamorous depictions of Hollywood actors and actresses who lead leisure-driven lifestyles are often portrayed, and are alluring to viewers who may idealize such luxury, indicating a trickle-down effect of upper class notions of taste to consumers of such media across an array of social classes. The widespread nature of modern technology implies that individuals across social classes have access to similar body ideals portrayed in the media through a variety of sources (Wykes and Gunter 2005). "Moreover, the mass media and the advertising industry constantly offer upper-middle-class culture as a model 
to members of other classes, who often come to emulate it or to define their identities against it" (Lamont 1992:1).

Celebrities, by nature of their high visibility in society, often adhere to societal notions of beauty and thinness. Award shows and film premieres are one way by which the celebrity image may be further disseminated to the public at large. However, the images that laypeople see in the media are often fabrications created by the entertainment industry, which involve public relations representatives, wardrobe specialists and makeup artists, various agents and managers, and others (Gamson 1994). "As carriers of the central commodity (attention-getting capacity), celebrities are themselves products" (Gamson 1994:64). Public image is strictly managed to give off a very certain and very calculated impression.

Advertising is another channel through which media images of the thin ideal female form can be disseminated to women in Western society. Advertising can be conceptualized as an institution that markets consumer goods and "manufactures the cultural products called advertisements and commercials" in an intertwined system of cultural symbols (Schudson 1984:5). Advertising has the ability to persuade consumers to make purchases of specific goods, as well as to buy into certain cultural notions regarding norms and standards, such as those for beauty. "The capacity of advertising to persuade is contingent upon the social and informational location of the consumer" indicating that an individual's background and social class might influence perception of the media being viewed or consumed (Schudson 1984:127).

While advertising functions in part through inspiring hope and a sense of possibility within consumers that encourages them to purchase a specific good or service, 
it also may lead individuals to engage in social comparison. Due to the nature of the advertising industry and its hyper-perfected imagery, individuals who make comparisons of themselves against such images will often find themselves to be lacking. "On the one hand, the media enlarge people's sense of their own and the world's possibilities; on the other hand, the media lead people to constantly compare themselves to others or to images of others" (Schudson 1984:155). The imagery utilized in advertising can be contentious in a variety of ways, targeting insecurities that individuals may possess, preying upon them, and enhancing personal discomfort about these insecurities with the objective of selling a product or idea. Ads typically say, "Buy me and you will overcome the anxieties that I have just reminded you about" (Schudson 1984:6). Women are frequently the targets for such campaigns, particularly those featuring cosmetics and fashion, which comprise industries that market their products to a target audience of female consumers.

Advertisements that contain imagery of models, particularly female models, often include subject matter that speaks to the female population who are exposed to these images. However, these images are often not true to reality, and often have been edited or Photoshopped to achieve a desired effect of a standard of beauty. A photograph may be manipulated in ways that are "faked, or, in varying degrees realistically mocked-up" (Goffman 1979:20). Goffman comments that this re-touching is particularly prevalent in images whereby "photographers routinely touch up negatives or prints to improve [for example,] the complexion of subjects appearing in them, creating a people that has smoother skin than that found among mortals" (Goffman 1979:21). Susan Bordo (2003) argues that modern women face even more societal pressures to achieve slenderness due 
to the digital manipulations of images that are presented in media images of a perfected female body.

For consumers of media, "the traditional position is essentially a gullible one, in which audiences want to be presented with believable illusions and, as long as imagemaking activities are effectively hidden, will believe what they read" (Gamson 1994:148). This is problematic because individuals who are exposed to such media are often not aware of the calculated manipulations that have gone into the production of certain imagery, particularly the thin ideal. Through hidden labor, such as diet or exercise, a woman may attempt to rectify her body in order to better match up to what might be for her an unattainable societal standard of beauty and appearance. To the public, she may wish to appear as though such undertakings are unnecessary, that she naturally and effortlessly looks the way she does, and that she eats as much as she likes. Goffman (1973) comments that "where the individual presents a product to others, [she] will tend to only show them the end product, and they will be led into judging [her] on the basis of something that has been finished, polished, and packaged" (p. 44). The finished product may be a body shape and size that adheres to societally prescribed standards of beauty, but "in some cases, it will be the long, tedious hours of lonely labor that will be hidden" (Goffman 1973:44).

\section{Impacts of Social Class Position on Body Image}

In addition to the media's potential to influence body image perceptions, social class can also mediate or impact body image interpretations that women have of themselves. Until the twentieth century, the middle and upper classes, not the working class, comprised the social group who possessed the money and leisure time to follow 
fashion, and furthermore, the means to experiment with various types of fashion and images (Orbach 1993). Sarah Grogan (2008) comments that "people with economic power have always set the standards for what is fashionable. This usually means that only the wealthy can afford to buy into the ideal" (p. 164). However, fashion does not simply refer to clothing, but also to an aesthetic concept, such as the fashionable body. These dominant ideals may have a trickle-down effect to members of lower classes, such as in the instances when individuals across social classes are exposed to media images that have been produced by members of higher classes (Simmel 1904). The lower classes may try to emulate the upper classes "in matters like cosmetics, clothing or home decoration" (Bourdieu 1979:57). Tastes of the upper class might also include a cultural disposition toward favoring particular ideals of beauty, a specific outward appearance of the body including not only shape but also adornment, and which contemporarily involves a more slender overall body type for women.

April Fallon (1990) argues that the thin ideal is more easily attained by those from a position of wealth, because individuals in these social classes often possess more time and financial resources to devote to certain practices such as going to the gym, investing in various cosmetics or surgeries, and becoming fashionably slender. While previous studies have linked women in higher socioeconomic status brackets to idolization of and the striving to attain an ideal body that is thin and beautiful, far less attention has been paid to working class women and how they might interpret such images and messages.

Bourdieu states that the most sought-after bodily properties are those involving slimness and beauty, and that these are "not randomly distributed among the classes," evidenced by "the proportion of women whose waist measurement is greater than the 
modal waist rises sharply as one moves down the social hierarchy" (Bourdieu 1979:207). Other studies have also found that in addition to larger waist size, higher BMI (body mass index) ratings have been linked to lower levels of educational attainment that are indicative of placement within a lower class, and low socioeconomic status groups are disproportionately affected by problems of overweight and obesity in the United States (Jeffery and French 1996; Molarius et al. 2000; Wang and Beydoun 2007). Bourdieu (1979) comments that it is not surprising "that petit-bourgeois women...devote such great investments, of self-denial and especially of time, to improving their appearance..." (p. 206).

Class-based values are important in the discussion regarding body satisfaction and social status. One study found that "a desire to be thinner was predicted by greater importance placed upon physical appearance and being from a higher social class" (Ogden and Thomas 1997:277). The researchers concluded that "social class is related to both weight concern and values," and the link between social class and weight concern is an important one (Ogden and Thomas 1997:278). A study by Wardle and Marsland (1990) concluded that there are social class differences in body concern, and this results in higher levels of concern among women who have higher social class backgrounds, which suggests that working class women may express fewer concerns. My study sought to address the need for further investigation of these concerns and the interpretations that working class women have of their bodies as viewed through a lens of culturally prescribed standards of beauty when faced with media depictions of the female body. 


\section{Body Image and Strategies of Resilience}

Much of the research on body image issues and thin ideal media depictions of the female body has been done by psychologists, and a smaller body of sociological research has focused on how women deal with this discontent, if at all. It is pertinent to take into account resistance and protective strategies in relation to media depictions of the thin ideal female body. The concept of resistance in relation to body image has also been called body image resilience (Choate 2005; McGrath et al. 2010; Snapp et al. 2012). In this context, resilience has been defined as "the ability to successfully cope with change or misfortune" in order to counter body image dissatisfaction (McGrath et al. 2010). Additionally, this concept is sometimes referred to as body image protective factors (Snapp et al. 2012). Snapp et al. (2012) draw upon research done by Cash and Pruzinsky (2002), and they contend that more research needs to be done on body image protective factors and resilience, focusing on the sociocultural factors that can contribute to body image dissatisfaction (p. 212). It is also important to study the body image protective factors that can help women avoid a negative body image (Snapp et al. 2012).

The notion of women's resistance strategies in regard to media depictions of the female body is a complex matter that may be under-theorized, particularly in the feminist ideology that body image issues in women are resultant simply of men imposing their will. Objectively, there are women in modern Western societies whose bodies do not match or resemble those in thin ideal female body imagery, for an array of reasons. However, there is a body of theoretical literature that addresses some manners and mechanisms that women may undertake as modes of resistance to dominating cultural ideals regarding standards of beauty and the feminine form. 
In a study regarding this issue, Rubin, Nemeroff, and Russo (2004) proposed that women can adopt strategies of feminist resistance in response to the conflicting messages about body image. They found that celebrating body diversity and scrutinizing the cultural messages about beauty that are implicitly conveyed through thin ideal media depictions of the female body can help to alleviate some of the anxieties associated with body image dissatisfaction. Another study draws upon these findings, and identifies how a critical attitude of how women are depicted and portrayed in the media "not only helps to ward off societal pressures but intervenes in the process of body dissatisfaction and allows women to maintain positive body images" (McGrath et al. 2010).

Choate (2005) hypothesized that body image protective factors include family of origin support (including supportive parenting and good parental relationships), acknowledgment of the contradictory expectations that exist for women, possessing a more positive physical self-concept in being aware of one's strengths rather than focusing on body shape, and utilizing more effective coping strategies overall. Another study had similar findings, and it also suggests that women who have more positive body images have "low levels of perceived sociocultural pressure from family, friends, and media regarding the importance of achieving a thin and beautiful ideal" (Snapp et al. 2012:211).

Additionally, educational attainment may be another factor involved in the cultivation of these cultures of resistance. In one study, McLaren and Kuh (2004) found that "education appears to be the key status variable contributing to body dissatisfaction" (p. 1583). They postulate that women with higher levels of education are better able to access health-based information, are more likely to know how to manage a healthy diet and body, and have an overall larger knowledge base regarding maintenance of one's 
health (McLaren and Kuh 2004). Women who have higher levels of educational attainment have also been shown to have higher levels of body image dissatisfaction, perhaps due in part to higher achievement expectations (McLaren and Kuh 2004). However, the majority of the literature on women's body image and resistance strategies have been conducted on college-aged, middle class women, and those that have focused on social class as a variable have not found any significant differences in body image related to socioeconomic status (Abell and Richards 1996; Rubin et al. 2004). For example, a study by Abell and Richards (1996) found that "no significant differences emerged on the overall body image scale, for either sex or SES [socioeconomic status]“ (p. 700). This indicates that working class women may be similar to middle class women in body image perceptions.

\section{Defining the Working Class}

A relevant issue to this study is class determination. Class placement must be determined before an investigation of the class-based repertoires that individuals may draw upon can be pursued. However, there are debates in the existing literature about how to define class, and defining working class can be difficult. Wendy Bottero (2004) comments, "Qualitative accounts indicate that people are reluctant to claim class identities" and if asked, it is likely that individuals will place themselves in the middle class (p. 987). Because of this, it is necessary to determine class placement by other means. Class has been conceptualized by Pierre Bourdieu (1987) as "sets of agents, who, by virtue of the fact that they occupy similar positions in social space (that is, in the distribution of powers), are subject to similar conditions of existence and conditioning factors and, as a result, are endowed with similar dispositions which prompt them to 
develop similar practices" (p. 6). For the purposes of my study, I have conceptualized working class as an amalgamation of concepts informed by sociologists, including theoretical insights from Max Weber and Pierre Bourdieu. Additionally, I have drawn upon class-defining concepts including occupation and educational attainment as the basis for class placement.

Certain types of occupations characterize the working class. Pierre Bourdieu, for example, noted that working class occupations consisted of those that are "skilled, semiskilled, or unskilled manual workers and farm labor" (Swartz 1997:161). In an intensive study of working class families, Lillian Rubin (1992) found that many working class women take on jobs such as "beauticians, sales clerks, seamstresses, cashiers, waitresses, office clerks, typists, occasionally as secretaries and factory workers; and at a variety of odd jobs such as baby-sitters, school-crossing guards, and the like" (p. 168). Working class male-dominated occupations include "plumbers, electricians, truck drivers, letter carriers, plant workers, painters, bank clerks, and other blue- and white-collar workers" (Lamont 2000:10). In this study, I asked participants about their current occupations, as well as the occupations of their husbands or boyfriends to better discern class placement. In addition, because social class can be generational, I also asked about the occupations of the participants' parents (Stuber 2006).

Defining class placement by inclusion of occupation is an approach much like that taken by Annette Lareau. Lareau (2011) incorporated the differentiation of types of work position (such as separation of managerial positions from positions without authority), occupational nature, as well as educational criteria such as credential barriers, to determine class position. In the case of Lareau's (2011) study, as with my own, I drew 
upon a categorical analysis by class, because a class-based perspective was useful for the purposes of understanding behaviors and practices. I investigated repertoires of resistance to media images of idealized bodies and protective strategies by which women maintain a more positive body image, which are inherently cultural concepts, and thus additionally required a cultural component of class for analysis. I based this research on the premise that members of the working class share similar ideas to one another in response to media depictions of the female body, and they may draw upon class-based repertoires in how they think about and react to these images.

Pierre Bourdieu's conceptualization of class is concerned with the boundaries involved in determining class (Wright 2008:335). Bourdieu also concerns himself with the topics of distinction within and between classes. As Swartz (1997) points out, Bourdieu "advances the bold claim that all cultural symbols and practices, from artistic tastes, style in dress, and eating habits to religion, science and philosophy - even language itself — embody interests and function to enhance certain social distinctions" ( $p$. 6). Bourdieu elaborates upon the nature of class in a concept he calls "cultural capital," which includes the various preferences and tastes exhibited by different classes as markers of class distinction (Swartz 1997). Bourdieu also draws from Weber's concept of status groups, and Bourdieu links material conditions to "the distinctive marks of lifestyle patterns and attributions of prestige and honor" (Swartz 1997:45).

Max Weber's concept of status links occupational divisions of labor with prestige. Occupations considered to be professional in nature are often held in higher esteem and accorded a higher status than lower level positions that require fewer training qualifications or education-based credentials (Scott 1996:36). For example, individuals 
who have obtained a college degree have been found to identify more with the middle class than the working class (Hout 2008:35). The implication for generational inheritance of class is linked to education in that the best predictor of obtaining a college degree is whether one's own parents obtained a college degree (Conley 2008; Lareau 2011).

Many sociologists utilize the measure of educational attainment to better ascertain class. For example, in her study of working class men, Michele Lamont (2000) used education rather than income to define class "because having a college degree is a strong predictor of high socioeconomic status and is one of the most powerful variables shaping life chances" (p. 253). Lamont's (2000) study, for example, included individuals who had a high school degree but not a college degree. For the purposes of my study, I took educational attainment into account when determining class. I specifically included individuals who have attended high school, who have a high school diploma or GED, or who have attended community college, but who do not hold a degree conferred by a university. Additionally, I asked the participants about their parents' educational attainment, and included participants whose parents do not have college degrees (Stuber 2006).

\section{Gaps in the Literature}

My research has built upon the previous research by addressing gaps in the literature, including addressing the need for additional research on body image protective factors (Snapp et al. 2012). Furthermore, there exists a gap in the literature regarding a thorough examination of working women and resistance strategies to media depictions of the female body. Because of this gap, it is important to investigate the subject of body image from a class-based perspective, and a crucial issue in addressing this research is 
the definition of working class. As many of the previous studies have been conducted involving convenience samples that included college-aged women, many of whom are middle class, it is essential to address the class-based gap in the literature by studying working class women regarding their experiences with body image in relation to the media.

The body is a site for the dissemination of cultural and social norms, and may be conceptualized as a location whereby class-based norms and discourses may be evident. While many aspects of body image, the media, the harmful impacts of thin ideal media imagery, discourses on class and its linkages to self-perception, and women's actions and behaviors in relation to thin ideal images have been studied, there does not exist a more thorough examination of how working class women interpret thin ideal images of the female body and the cultures of resistance or protective strategies that may arise as a result.

Research conducted by Ogden and Thomas (1997) found that "values concerning physical appearance, achievement, and family life may be important," and that "the results also provide support for a direct link between these factors which as yet remains unexplained" (p. 278). This demonstrates a need for greater research on class-based values in relation to body image. As previously mentioned, the research conducted by McLaren and Kuh (2004) found that women who are socially advantaged tend to experience higher levels of body image dissatisfaction than do women who are less socially advantaged, and also indicate a call for additional research. Their findings indicate that women who have higher incomes and higher levels of education experience more negative body image perceptions. However, "although various indicators of socio- 
economic position have been examined in relation to body dissatisfaction, it is not clear which indicator is most important in this context," indicating a need for further study of the relationships between social class and body image (McLaren and Kuh 2004:1576).

While existing research does demonstrate that linkages between social class and body weight exist, previous sociological studies have not fully explored the possible linkages between social class and women's resistance cultures to media depictions of the female body. Wright, O'Flynn, and Macdonald (2006) state that "there has been far less examination of how these discourses and practices have been 'variously taken up, negotiated, or transformed' . . by individuals, beyond quantitative studies of body dissatisfaction and body esteem," although this research does not deal directly with working class women (p. 707). However, it is far too simplistic to say that working class women simply accept the thin ideal images they see in the media and in advertising, internalize the message as negative when they find their own bodies do not match up to this ideal in comparison, and internalize the resultant attitude of feeling bad about themselves because of their body types. Rather, working class women, like women of other classes, have devised ways to resist, avoid, ignore, mediate, and cope with thin ideal media images, and these strategies are likely cultural repertoires of their class backgrounds that these women use to assist them. The complexity of these various issues indicated qualitative in-depth interviews as a research approach, because this approach enables researchers to gain more understanding of participants' opinions and experiences of their bodies from the participants' own perspectives. 


\section{RESEARCH DESIGN AND METHODS}

\section{Sample and Data Collection Methods}

This qualitative research study used in-depth interviews to learn how working class women interpret media depictions of the thin ideal female body. Additionally, attitudes toward these images, personal interpretations of body image, and resistance and protective strategies were investigated. In-depth interviews were preferable over surveys for this type of research because using open-ended questions enabled participants to share their thoughts, opinions, and stories on a variety of subject matter relating to body image and the media, without the constraint of a predetermined set of response categories. A semi-structured interview guide was utilized throughout the research process to guide the interviews, allowed for further questioning, and participants were encouraged to elaborate on the topics they felt most passionate about. The main topics of the interview guide included questions regarding information on the participants' backgrounds, questions to elicit the participants' viewpoints on the effects of thin ideal media imagery of women's bodies, questions about the participants' lifestyles, and finally, questions discussing participants' resistance or protective strategies to cultural messages about the cultural values of beauty and the appearance of the body.

This study included interviews of eleven white working class women between the ages of twenty-five and thirty-five. All women in this study reside in the Midwestern United States. Women in this age cohort were chosen because they were most likely to have had the time necessary to complete their educational attainment goals, and were also likelier to be employed in an occupation that was indicative of class placement for the purposes of this study. Additionally, women in this cohort were likely experiencing the 
first noticeable effects of the aging process (such as physical indicators including weight gain during and after childbirth or married life, the appearance of wrinkles, and noted decreases in metabolism), and these signs contradict the standardized beauty ideals of women that are typically portrayed in the mass media.

Media depictions of the female body were conceptualized for the purposes of this study as instances where imagery of the thin ideal are produced in a medium intended to reach a broad and national audience. Such images are featured in the appearance of celebrities in various films, TV shows, music videos, and public appearances (such as televised award ceremonies or red carpet events), in the appearance of models at fashion shows, and in advertisements such as those on television, online, in magazines, on billboards, and elsewhere. I have chosen to study working class women's reactions to media depictions of the female body from a sociological perspective because the mass media in particular are influential in conveying sociocultural standards and messages (Thompson and Heinberg 1999).

The most concise measurement of social class that I utilized to discern working class placement was two-fold in nature: the participants and the participants' parents did not hold a bachelor's degree, and the parents work or worked in low-skilled service or manual occupations (Stuber 2006:292). For these purposes, a series of screening questions was employed at the onset of the interview process. Because of the likelihood that participants would not readily provide income-specific information during the interview process, it was necessary to define working class by these other factors, such as occupational status, educational attainment, and questions posed about the occupational status and educational attainment of the participants' parents and significant others. 
Although participants were not asked to place themselves within a given social class, existing sociological literature would classify women with these characteristics as working class.

In this study, purposive sampling methodologies were utilized, whereby "researchers use their special knowledge or expertise about some group to select subjects who represent this population" such as working class women (Berg 1995:179). A hybrid sampling approach was also employed, which drew from a convenience sample of individuals the researcher knew who fit these criteria, and then requesting that those participants suggest an additional person to be interviewed, such as in snowball sampling. Because of the nature of snowball sampling, confidentiality amongst participants could not be guaranteed, because by suggestion of others to be included, there was an awareness of who might be interviewed for the study. In order to protect participants' identities, specific identifying information that could be used to link responses with participants has been omitted from any documents accessible to the public.

Prior to conducting the interviews, each participant was given a letter of informed consent that detailed the topics that would be discussed during the interview process, as well as contact information for the co-principal investigator and the university's research ethics and compliance office. Each participant was required to sign the informed consent form before the interviews commenced, and an additional copy was given to each participant for future reference. Additionally, participants were informed that they were not required to answer any of the questions if they did not wish to do so, and that they could withdraw from the study at any time. 
Although eleven women between the ages of twenty-five and thirty-five were initially interviewed, upon closer inspection of the transcribed data, only nine of these interviews were included in the actual study for analysis. The two interviews were eliminated because during the interviews it was revealed that these women had obtained bachelor's degrees, and one woman particularly identified with her family's Hispanic heritage. The reason why this particular participant was not included is because it is possible that issues of race and ethnicity may affect body image perceptions, particularly in relation to media depictions of women, and for this reason, the women who were included in this study were Caucasian.

The participants' ages were as follows (in ascending order): 26, 26, 27, 28, 28, 29, 29,30 , and 35 years old. Of the participants, two had not completed high school, and of the rest who had obtained high school diplomas, three reported having some community college exposure, and one additional participant had formally obtained her associate's degree. The highest level of educational attainment of the participants' mothers ranged from junior high in one case to high school diplomas, two with additional exposure to community colleges, and one with a community college degree. Fathers' highest levels of educational attainment included high school diplomas, and four with associate's or trade school degrees. The highest level of educational attainment for the participants' partners or spouses included junior high, some high school, a high school diploma or GED, some college, and one associate's degree. Four participants reported having no children, one participant reported having two step-children, another participant had her own child and two step-children, an additional participant had two children, and the remaining two participants had one child each. 
Data Management and Analysis

The interviews were conducted between December 2013 and March 2014 and were recorded by an audio recording device. Each interview lasted approximately sixty to ninety minutes. While some of the interviews were conducted in person, others were conducted by phone after informed consent had been obtained. For interviews conducted by phone, participants agreed to be contacted via email, and a copy of the informed consent letter was digitally attached to an email message and sent to them. Participants then signed and returned the informed consent letter to the co-principal investigator. The interviews were then transcribed within a week of the interview itself.

Transcription of the interviews was imperative for analysis because a written format is more accessible and facilitates overview (Kvale 2008:169). Transcriptions were not necessarily transcribed verbatim, however, as some pause words, such as "uh," "um," and "er," were omitted where they were not pertinent to provide context to the interview. More drawn-out pause words, false starts, and fumbling for explanations, such as in the case with sensitive topics, were included where they were relevant. Because some instances of filler words, such as "like," or "you know," were not pertinent to the overall scope of the research, these were also omitted from the transcriptions in some instances. Notes regarding intonation, laughter, pauses, sighs, and other auditory cues were additionally noted in the transcriptions.

Data analysis was undertaken using grounded theory. This method involves the creation of "codes by defining what we see in the data. Codes emerge as you scrutinize your data and define meanings within it" (Charmaz 2006:46). Grounded theory is an inductive technique for data analysis. This approach to research starts with raw data, 
analyzes it, and eventually theory is formulated from the findings. After the data were transcribed, they were first coded using a process called initial coding, which involved coding incident to incident within the data transcriptions (Charmaz 2006). This coding process resulted in a multitude of codes. After all interview transcriptions were initially coded in this manner, they were then coded again using focused coding, which was more directed and made use of the emergent analytic themes. "Focused coding means using the most significant and/or frequent earlier codes to sift through large amounts of data.

Focused coding requires decisions about which initial codes make the most analytic sense to categorize your data incisively and completely" (Charmaz 2006:57). Focused coding also enabled certain recurring codes to be filtered out or grouped into larger theoretical categories.

Data, in the form of quotations, were then analyzed in comparison to one another, and similarities and differences arose when investigating participants' responses in this manner. Furthermore, findings about these women were compared to the findings in the research literature about middle class women for class-based analysis. Throughout the process of data analysis, memo writing was also utilized as an analytic tool in treatment of the data. Memos were written during the process of analysis in an attempt to study the emerging data, seek out processes and investigate particular motifs, as well as categorize the data by tracing the participants' assumptions and beliefs that supported or opposed certain overarching themes.

\section{FINDINGS}

In this study, working class women were interviewed regarding their perceptions surrounding the issues of social class, the effects of the media, and body image. 
Throughout the course of the interviews, the participants reported on their interpretations of these issues, and the findings suggest that social class placement is not a particularly prominent or salient lens through which the working class women included in this study interpret their realities in relation to their bodies. Furthermore, the findings suggest that working class women are similar to middle class and college educated women in their interpretations of the negative effects of the media in relation to body image perceptions. The working class participants in my study reported enacting and engaging in resistance and body image resiliency strategies that protect, absolve, or help them to mediate the detrimental impacts of the thin ideal and culturally-prescribed standards of beauty, and these strategies were similar to, and at times, identical to strategies that middle class women utilize for these same purposes.

\section{Working Class Women's Interpretations of Social Class and Body Image}

This study investigated the linkages between social class and interpretations of body image and the media. This study found that the working class women in my sample echoed the findings in previous studies of middle class women in their interpretations of their bodies, their awareness of media depictions of the female body, and the resistance strategies they employ to counteract the negative body messages they experience. The wealthy elite control the media and therefore its messages, and this class has the economic power and other resources necessary to better achieve such standards for beauty in regard to the body aesthetic (Grogan 2008). It was therefore important to investigate whether other classes attempt to emulate the upper classes in regard to bodily appearance. 
As a component of class analysis in the interview guide, participants were asked whether they believed individuals with different class backgrounds have bodies that have different appearances, particularly in regard to the bodies of the very rich and the bodies of the very poor. In response to this question, one thirty-five-year-old woman commented,

You know, I think the upper classes, they might think...that they need to...fit the standard or the ideal of the perfect woman, the perfect man....I think that they might focus a little bit more so on that, but I think that in the lower class, that they also...feel that they need to look a certain way, but maybe it's not as prevalent.

Many participants in this study commented that people with access to more money often have more resources in the way of time and finances to devote to the attainment of the thin ideal. Another participant stated,

I do think, well if you have money, especially if you have a significant amount of money, you have access to things like personal trainers and dieticians and nutritionists that can work out meal plans for you, and if you're talking lots of money, you could even get into the whole personal chef thing. So I think that their resources are a little bit broader. And I think that somewhat because when you start to talk about money, you start to talk about success. You know, people most always think that money equals success or vice versa, which isn't always true.... But then...the rich and the famous are usually thin.

Because the wealthy have access to greater resources, it is easier for them to attain the cultural standard for beauty that equates thinness with increased physical attractiveness (Fallon 1990). Another participant commented similarly, stating, "They can afford to do all the different diets....'Cause diet food is usually more expensive than the junk food....So they can afford to get all the organics and healthy things and the treadmills and all that. I'm sure they're way different."

Other interviewees indicated that they did not necessarily delineate marked differences between the ways in which the bodies of individuals in various social classes 
look. When asked whether she believed that people from different social class

backgrounds have bodies that look different, a twenty-eight-year-old mother stated,

I mean, I guess yes and no. I think that there are different ways that people look no matter what....I don't think it matters... whether people have money or not. Whether they do, they have the ability to join a gym or buy nice things or do detox, or people that don't have much money can't necessarily do the expensive things. But I don't think that they necessarily look different. I think that whether you have money or not, everyone struggles with body image at some point in their life.

The participant mentions that she perceives body image issues to be a pervasive issue for individuals, and indicates that this is true for most people, regardless of class position. Another woman, aged thirty-five, commented on this issue as well. She reported,

I would say that it would seem that way. The richer people have...a more confident outlook, but that's not necessarily true. And the poor people have a...less confident outlook....I think it's kind of even that people that are struggling in the lower class; I think there's people that are struggling with the same things in the higher class and upper class.

Although some of the participants in this study identified the ability for individuals from wealthier backgrounds to afford certain products, gym memberships, or types of food that may lead to a more slender body type overall, some participants were also cautious to make sweeping statements based on the issue of social class alone. Furthermore, although the working class women in this study did perceive some differences between the very rich and very poor, social class was not a frame through which they reported upon their perceptions of their own bodies. When asked to describe their own body types, participants spoke in general, descriptive terminology. As one woman described herself, "I would say not plus, but not average. And the reason that is is I have to buy in certain areas for the top half of my body and in certain areas for the bottom half, so definitely not the hourglass figure." Another woman expressed, "My 
personal body type? I would say...like J-Lo [celebrity Jennifer Lopez]. She's got the butt, I've got a butt, so I would say that she's probably one of the people that I would be closer to in body type." In their discussions of their bodies, women were often short in description, and framed their descriptions in terms other than social class. When asked how she would describe her body currently, one participant said, "Hourglass with extra minutes. [Laughs]....I actually generally like my body. I have a bit of a tummy, but...I like the way I look.” Another participated simply stated, "Average. I would say average.”

While the working class women who participated in this study were able to discuss, compare, and at times, contrast differences in bodily appearance, the framework of social class position did not emerge as a particularly notable or prominent issue through which these women contextualized body size. In addition, participants did not report that class was an objectively salient issue that came to bear upon their own awareness of their bodies. Throughout the interview process, participants in this study did not express an explicit consciousness of the ways in which social class might act upon others' bodies, their own perceptions of their bodies, nor their perceptions of their bodies in relation to the thin ideal images of the female body that are prevalent in the mass media.

Working Class Women's Perceptions of the Effects of the Media on Body Image

In this study, participants were interviewed and asked questions regarding their perceptions of the media's potential impact on body image. Each participant reported that the thin ideal and hyper-perfected imagery of the female body had some negative implications, and there was a range of intensity of these implications in their responses. Such response patterns iterate findings from various previous studies that have looked at 
the effects of the media on body image from both psychological and sociological viewpoints, indicating that the working class women in this study are similar to women in other social classes in this regard. For example, one study by Rubin et al. (2004) explored middle class women's awareness of the negative impacts of imagery of thin ideal female bodies as well as the media messages about feminine beauty, and this awareness was reiterated in my own study by the working class women who participated. Some common themes that arose during this portion of the interview included the negative effects of the media in setting a standard for beauty in women, an awareness of the deceptive practices that the media utilize in portraying the thin ideal female body type, as well as some positive effects that the media could potentially have, such as advertising campaigns that are more inclusive of a diverse range of body types.

Educational attainment. Previous literature on the study of body image has made the argument that education seems to be a key factor in teaching women about the negative influences of the media, particularly in regard to thin ideal depictions of the female body (Albright 2007; Chambers and Alexander 2007; Grogan and Wainwright 1996; Jeffery and French 1996; McLaren and Kuh 2004; Trottier et al. 2007). While previous studies have focused largely on college-educated women and their perceptions of the media's influence in relation to body image, the working class participants in my study also expressed some of these sentiments, such as the negative impacts that these images can have, an awareness of the deceptive practices in the media, as well as insight into the lack of depictions of average women in the media. In contrast to collegeeducated women, however, the participants in my study were selected for inclusion because they did not hold bachelor's degrees. Despite the lack of college degrees, the 
participants in my study articulated a similar awareness of the media's practices as college-educated women.

Participants in my study recognized, just as middle class women do, that thin ideal media depictions of the female body can have a negative influence, indicating that these kinds of images can set a standard for how women's bodies should look. When questioned regarding what that standard the media might set for women entailed, participants' answers varied from detailing different parts of the body that should appear in a certain way (particularly the appearance of a smaller waist and larger breasts), but also focused on the connection in American society between thinness and beauty. Furthermore, this equation with a slender physique with beauty can lead to an idealization of a narrow preconceived set of notions about how one's body should appear in society, and can have the impact of putting pressure upon women of what they should strive for. When questioned about how women's bodies are depicted in the media, one participant responded,

There was some article I saw online, something about a realistically proportioned Barbie. They had taken the measurements from some 18-year-old girl, and computer generated it into what a Barbie would look like if they used actual measurements...I remember reading the comments of that. People were really nasty about it.... like, "Oh my god, she's hideous, she looks like she's super fat." ....So I guess I feel like the media has turned people into that point of view....If it's beautiful, it has to be really thin and perfect, and that regular bodies, just the way they are, are not beautiful.

That these thin ideal images of female bodies are both unattainable and yet still remain templates for idealization for many women is problematic, particularly because the media tend to portray one rigid set of standards for beauty emulated in the thin aesthetic, while many women in the United States have bodies that naturally do not 
match up to this ideal. Negative ramifications for body image can arise when women recognize that their bodies do not inherently resemble the bodies they are confronted with in these media images, and many of the participants additionally revealed that they believed other women in society would like their bodies to more closely resemble the ideal that they see in the media. When asked if she thought that other women's body images may be affected by these images, one participant reported,

Most women look at these images and think, "God, I wish that was me. I wish I was that skinny. I wish I was that pretty." And in reality, if that would really see some of these models in real life without makeup, without anything, they'd see that they [themselves] are much more beautiful than these models. Some of them [the models] are anorexic, they have major eating disorders. It's awful, but it really puts down a woman's self-esteem, her confidence levels, everything.

An interesting distinction arose during the early interviewing process between the way women are depicted in fashion magazines and advertisements and the way women are depicted in fitness or health magazines. The distinction that one participant made is that while fashion magazines tend to portray very thin women, the focus of fitness magazines is to portray women who are physically healthy in an athletic sense. I found this particular distinction to be so interesting that I ended up incorporating this concept as a question in subsequent interview guides. One participant elaborated on this concept:

Well, I think it depends on the media, like the magazine itself. Like I said, Shape magazine, and Firm, and those types of magazines, I think they have a better depiction of women in their different sizes. I still think that the fashion magazines and Us Weekly, they're still depicting women, you don't see a lot of variety [of body types].

Similarly, another participant commented,

It's like, I've heard this a million places before, but fashion magazines, the girls are just there to be [clothing] hangers. They're there to be thin and show off the clothes, and not to necessarily be healthy, but to make the clothes look good. And 
in fitness magazines, they're basically more accepting, maybe not in their ads, but more in their articles - maybe even in their ads — of girls having more solid builds and more muscular builds that maybe wouldn't be considered as beautiful for fashion ads.

In addition to discussions of these differences in bodily presentation across different media, participants also commented that when given the choice, they would prefer to see a healthier body type depicted. One participant spoke more about this topic:

I think women in fashion magazines need to eat about ten more cheeseburgers than the women in fitness magazines. I think fashion models are extremely, extremely unhealthy, and people just put such a blind eye to their lifestyle....But, you know, women in these fitness ads, I mean, yeah, they look great. But they also look fit, they look toned, they don't look hungry. I think that's a big thing.

Many of the women in this study commented upon what they perceived to be deceptive practices on behalf of the media when women's bodies are falsely represented. These false representations were reported to manifest in a variety of ways. Many of the participants mentioned the use of Photoshopping and airbrushing techniques on static images in advertising, with the objective of depicting a perfected ideal in terms of even skin tone and contoured body type. Additionally, some participants also mentioned the use of fashion design specifically for the body types being displayed in order to make those bodies and fashions appear more intrinsically appealing. Many participants identified that the purpose of much of the advertising and use of such media depictions of the female body was a marketing tool to sell products to women.

On the topic of deception, one participant commented that the media often report misleading information in terms of the accuracy of celebrity weights or dress sizes. When asked about her thoughts of how women's bodies are depicted in the media images that she encounters, she responded, 
I don't like it. I don't like that Kim Kardashian is considered a size 2 when clearly she isn't. I like the fact that they are starting to appreciate curves on a woman. That's good, 'cause when I was growing up that was not the case. Heroin chic was the look. So I like the fact that they are appreciating curves more. I still think that it's not where it should be....Like I said, Kim Kardashian being a size 2, to me, is not right.

Here, the participant recognizes the disconnect between reality and messages that the media suggest to women about these issues, because of the participant's implication that while the media report this celebrity as being a certain size, in reality, she is likely not.

Previous studies of college educated women have shown that these women possess a critical comprehension of the media's use of certain techniques to manipulate or enhance images of the female body to achieve a slender aesthetic (Ballentine and Paff Ogle 2005; Grogan 1999; Grogan and Wainwright 1996; Milkie 2002; Rubin et al. 2004; Thompson and Heinberg 1999). The findings from my study indicate that working class women and middle class women express similar levels of awareness of deceptive practices in the media, suggesting that educational attainment is not a platform by which this information is obtained, and furthermore indicates that women from different social class backgrounds have access to similar information in this regard. One possible reason for this is that these media are particularly salient throughout social classes in society, and that women from different social class backgrounds may have similar levels of access and exposure to the same types of information throughout the media. For example, one study of Seventeen magazine found that

"some content addressed the assembly of an über body and the self-care practices or bodywork routines that could be undertaken to achieve it....In other instances, however, content urged readers to resist cultural discourses perpetuating narrow norms of attractiveness....Here, bodies that were problematized in other articles as 
unacceptable and in need of 'work' were reframed as acceptable and even valuable" (Ballentine and Paff Ogle 2005:301).

In my study, educational attainment did not appear to be as important a factor as media exposure may have been, although this facet was not as thoroughly or directly investigated. However, it is likely that women in various social classes have similar levels of exposure to the thin ideal, as well as body acceptance campaigns that serve, in part, as educational platforms through which discussions of the negative impacts of thin ideal imagery may be disseminated. A recent pathway for critical interpretations of the media's preference for beauty as defined by the thin ideal has been the emergence and increasing prevalence of body acceptance campaigns.

Many of the participants mentioned that the media have made some improvements over the past several years, particularly with the inclusion of a wider range of body types through the use of plus-size models in body acceptance campaigns, what one participant labeled as "Any Size Campaigns." Several companies in recent years have begun to openly include a diverse range of body shapes and sizes in their advertising, and have been very visible about taking these actions. However, among the participants who mentioned such campaigns, feelings were mixed about their intentions and effectiveness. One participant mentioned "I know Victoria's Secret says they have an any size campaign, but it's like, any size of tall, skinny. [Laughs] Like, okay....”

However, later, the same participant mentioned that such campaigns can have a positive effect in celebrating body diversity and different types of beauty in women. She said,

I think they're going in the right direction by getting more body types and more everyday women....There was another magazine that I saw the other day, or another ad campaign, that they decided they're not gonna airbrush their models. So some of them have rolls and stuff. And, it's like, these women are gorgeous. 
Another respondent reported "In some cases, it's gotten better. Like, with some commercials, like Dove commercials...they show women who are real women..." While overall, the majority of participants who were aware of the existence of such campaigns tended to see them as more positive than negative, they also reported that the media have a long way to go in terms of improving upon the inclusion of body diversity, particularly in advertising.

Although the working class women in my study differ in levels of education attainment from the college-educated women of previous studies in the literature on body image and the media, the participants in my study expressed similar levels of awareness of the negative impacts of the thin ideal, as well as a comprehension of the deceptive practices that the media may engage in. Because working class women identify these factors in a manner that is similar to the ways in which educated women do, these findings indicate that formal educational attainment is not a prerequisite for the cultivation of a critical awareness of the media or the practices employed. Because the media can hold contradictory values simultaneously by displaying the thin ideal and providing information about resisting these messages about standards for feminine beauty through body acceptance campaigns, women are provided in this sense with a context through which they can analyze the media, perhaps provided by the media itself.

\section{Working Class Women's Understandings of Their Own Bodies}

While the media can provide a contextual platform through which beauty ideals are disseminated and by which individuals may engage in cross-comparisons, working class women in my study reported that there are other mechanisms at work in their lives that influence how they perceive and inhabit their own bodies. One strong thematic 
element that arose during the course of this study was the value of health over appearance. Working class women in this study reported viewing the thin ideal images they encountered in the media as unhealthily thin. In comparison, there was a consensus in stating that they viewed their own bodies, while imperfect, as healthier. This inversion of meanings indicates a resistance tactic that is being utilized to some degree by working class women in response to the thin ideal images and corresponding societal values regarding standards for beauty. In essence, the participants in this study use this strategy as a way of distancing themselves from these images and value systems by incorporating a changed meaning of implied health that better suits their own body shapes. One participant, a twenty-six-year-old woman, stated, "They're very bony, almost sickly looking. There's a difference between healthy and being thin, because I know a lot of girls that are naturally very thin, and they don't look sick." Similarly, another woman, a twenty-six-year-old mother, said of the media,

It's a very strict, I mean they try to go for the hourglass figure usually, and very, very tiny....A lot of the models, they literally have nothing. I think they look disgusting, personally, but when you see 'em on the runways and stuff, they look awful. They literally have nothing, no boobs, no butt, no nothing.

Additionally, a twenty-eight-year-old mother of one commented, "I think it's morally grotesque because it shows women who are size zero and no one's a size zero.”

Several of the participants also mentioned the almost inhuman proportions of the women depicted in the media, referring to them as "alien" or "alien-like." Many of the participants agreed with the sentiment that being too thin was unattractive, and one woman commented that "I think that nowadays most of them are disgusting, 'cause they're too skinny. They look almost alien-like." Another participant mentioned that in 
relation to the relative height of fashion models to which she has compared herself, that these women in the media are extremely dissimilar to her in appearance "because I'm short and chubby, I don't have six legs, I'm not an alien. It shouldn't be this difficult." Here, the women have conceptually distanced themselves from the thin ideal by reinterpreting its meaning as both sickly as well as drastically unusual in such a way that deviates from the perceived norm that they consider to be acceptable for their own bodies.

In contrast to the unhealthy thin appearance of some women in the media, when asked to describe how average women in real life look, a twenty-seven-year-old woman in this study reported, "They have curves. They eat.... They work out and everything, but they're healthy. They look more healthy." Health was valued amongst participants more than physical appearance, particularly in contrast to the thin ideal depictions of the female bodies in the media upon which the women in this study were asked to comment. Overarching themes of sickliness and ill-health in association with dramatically slender women in the media contrasted with the motif that the participants reported in relation to their own bodies, considering themselves to be healthier and more normal overall. Other factors also contributed to the participants reported inhabitancy of their own bodies, and these included changing priorities and value systems as they move further through their life courses.

Significance of age and experience on body image perception. An overarching theme that emerged throughout the course of the research process was the concept that age and life experiences can contribute to the ways in which participants reported they experienced their bodies in relation to the media. Specifically, participants mentioned that 
the importance and influence of the media is no longer as great to them personally as it once had been, and that such matters had more relevance when the participants were younger, such as in their adolescent or teenage years. In response to a question regarding the media's influence in her life, one participant commented,

You know, when I was a teenager....I was eating like a teenager does. It wasn't until I got into my late 20s and I realized that my 30s were coming up on me that I was like "Fuck, this is the best my body's gonna be. It's gonna be all downhill from here, so I might as well start taking really good care of it." And I think a lot of people have that realization, especially when they're coming up on 30, of like "Hey, I'm not a kid anymore. Maybe I do need to start being a little bit healthier with myself."

In this instance, the participant mentions attempting to adhere to the media-proscribed thin ideal through engagement in exercise, though she indicates in her later commentary that this initial approach may not have been a healthy one, since she mentioned she had been eating "like a teenager" at the same time. In contrast, another participant touched upon her struggles with an eating disorder as a teenager:

I mean, I used to really focus on the media. It was a problem, when I was in high school, you know, the eating disorder and things like that. So, I focused heavily on the media and what the actresses looked like, the models looked like. Now, I don't care...I'm more concerned with how I feel and how I look. And yeah, I know that there are some trouble spots to take care of, but mostly I don't look towards other things in order to feel better about myself or how I should feel about myself.

Even though these two participants report differing experiences in their adolescent years, the emergent theme of prioritizing one's health and wanting to feel better about oneself were similar in both instances.

Previous studies indicate the various negative impacts that repeated exposure to thin ideal depictions of the female body can have on young women. Interestingly, participants in this study agree that as they have gotten older and as their bodies have 
changed in a way that deviates from the thin ideal, that they strive to be more accepting of themselves. One study has detailed that the fastest weight gain increase in American women typically occurs between the ages of twenty and thirty-four years of age, overlapping with the participant sample of twenty-five to thirty-five years of age (Wang and Beydoun 2007). In fact, "weight gain is normative with advancing age" (Hurd Clarke 2002:751). In this regard, one participant commented, "With age comes acceptance. You know, at this point it's not so much let's talk about our bodies and how they're bad, but...let's talk about our bodies and what we can do with them. And that's a good thing." This coincides to some degree with research that states that "older women prefer more curvaceous female bodies as well as a broader range of ideal female shapes and sizes than their younger counterparts" (Hurd Clarke 2002:752).

Another participant spoke at length about how being thirty-five prompted her to focus less on the media's messages about what her body should look like. When posed a question regarding whether or not she and her friends discuss issues related to body image, she noted,

Um, not so much anymore. I think that the age that I'm at and where my friends are, I think it's less of a topic. You know, somebody might have a bad day and feel down, and then get down about everything else...but... we don't generally have conversations like that anymore....In high school...that's when you tend to worry more so about that....You haven't experienced much of life....The older you get, obviously, the more experience you have, and...that stuff becomes less important - when you have responsibilities, and you have to be an adult. Now, that's kind of a thing that doesn't seem to, at least to me, it doesn't seem to be one of those things that I generally worry so much about.

Here, the participant cites that with aging comes experience, and through that process, certain societal pressures regarding bodily appearance become less important. She puts this into the context of "being an adult," and mentions that while she still has days where 
she experiences some negative emotions associated with her body, that conversations about such subject matter were much more common when she was in high school. Because many of the women included in this study had no formal credentials from institutions of higher education (although some had attended community colleges), it is interesting to note that for most of the participants, high school is their last educational frame of reference.

The effects of childbearing on body image perception. An especially meaningful factor that participants mentioned as having contributed to the changes in their bodies and their bodily divergence from the thin ideal was the effects of having children. Though not all of the participants included in this study were mothers, of those who were, each cited motherhood and the changes that occurred to their bodies during and after pregnancy as influential forces in both their bodily appearances as well as their interpretations of their bodies. Of these women who had experienced pregnancy, positive associations were generally reported in the candid discussion of how pregnancy affects a woman's body.

When asked about whether having children changed or influenced the way in which she thinks about her body, one twenty-eight-year-old mother of a young boy stated,

Well, I can't fit in the clothes, like the pants I had before him.... The hormones can either change for the better or for the worse, and mine did it for the worse....So knowing the change that took effect and knowing that I can't get back down to where I was before because of the change that took effect. Your body changes in ways that you'll never understand until you have a child. Your hips change, they turn out. Your pelvic area changes, your hips, your waist, your ribs, it all changes. So, people who are the same size, they're very proud of themselves, but people who can't get back down to that size, they learn to acclimate to who they've become and they treasure it. My son was a godsend to me so I don't take it any way. 
In her recollection of the changes her body underwent during her pregnancy with her son, this particular participant was very frank in her discussion of how her body changed as a result of her pregnancy. However, she also mentioned that for women who do not return to their pre-pregnancy size, women can learn to live with the way their bodies look. This participant uses positive terms in relation to how women interpret their post-pregnancy bodies, including that women come to "treasure" their new bodies, and that she considers her son a "godsend," indicating that she does not harbor negative associations regarding this issue. This positive interpretation of the self can become even more important with subsequent births, as "with each additional birth the amount of weight that is retained increases in magnitude either because of pregnancy-induced metabolic changes, or because the woman is increasingly less able to lose weight due to the greater availability of prepared food in the household and because there is less time to engage in regular exercise" (Williamson et al. 1994:567).

Another woman, a twenty-eight-year-old mother of a baby girl, comments that she had to learn to love her body again after her pregnancy. She stated,

Having a child changes everything about your body, and you have to learn to love your new body whether or not you lose the baby weight or not. There's things about your body that just change. So it's definitely a huge learning process. You have to learn to love yourself all over again. I think personally for women, maybe depending on whether you have postpartum [depression] or not. I didn't have any, but I still had to work through a lot of that stuff, so I think there are different elements within it, that, yeah, for sure changes everything. It changes what you think about yourself, it changes, it changes everything, for sure.

This woman alludes to the marked bodily changes that transpired during pregnancy. She also indicates that women can and do learn to love their bodies, even after their bodies have undergone such drastic transformations. A prior study also comments upon this 
facet of motherhood, whereby "semi-structured interviews of pregnant (or immediately post-partum women show that they are generally positive to body changes during pregnancy and are more accepting of their body size and make fewer attempts to control their weight than their non-pregnant peers" (Tiggemann 2004:35). When asked about whether the thin ideal affected her positively or negatively, this same participant drew upon her experience as a mother to describe her experience. In regard to the media's influence, she said,

It doesn't affect me negatively. I'd say it probably did when I was younger. You want to look like them, you wanna be accepted...But as I've grown, I don't feel - I feel like I'm looking at it in a different way probably, because I now have a little girl, and I'm kind of past that, at least for me personally. I don't feel that affects me, other than motivation to be healthy and look good within my own realm of being healthy and looking good, you know? But, so it doesn't affect me now, but it for sure did when I was younger.

This participant echoes a sentiment that other participants also mentioned. Instead of valuing the culturally proscribed standards of beauty that are often displayed in the media as adherence to the thin ideal female body, this participant instead details other value systems that take precedence, including her life experience, her health, and her role as a mother.

Participants in this study cited how both age and life experiences were important factors to their own body acceptance. In the body image literature, one early study on this issue found that across the life span, women reported a decline in their rated importance of an interest in appearance (Cash et al. 1986). Another study found that as women move through their adult life course, weight and appearance become less important sources for self-esteem, and other factors, such as experiencing motherhood or gaining more occupational experience can be more important (Tiggemann 2004). Tiggemann (2004) 
additionally comments that "the body does seem to become less central to older women's overall view and feelings about themselves than is the case for younger women" (p. 34).

The participants in the research study also indicated that other factors have become more relevant to them throughout the progression of their adult lives, and although in many cases they identify an increase in body weight as coinciding with increased age, they place less emphasis on these issues and issues regarding media ideals for bodily appearance. Their reported reasons for weight gain, in conjunction with the progression of age and engagement in various landmark life experiences, coincide with previous research, where it was found that individuals "continually shifted between a self-blaming position and a blame-absolving position" whereby "none of their explanations about weight gain were put down entirely to their own actions, or, to factors perceived as beyond their control" (Greener et al. 2010:1044). Although body image is greatly affected by a woman's feelings about her weight, age and experience are significant factors that working class women reported to affect their body image perceptions (Hurd Clarke 2002).

While the working class women in my study did not demonstrate a consciousness regarding the ways in which social class position may interact with their interpretations of their own bodies, they did report that age and experience were both important in terms of their body image interpretations. Some of the participants commented that age and experience can lead to a greater acceptance of the body, as it can guide an individual to have a greater acceptance of her body. One possible explanation for this is that these women have referent peer groups who are similarly going through such processes, and that the bodies of these peers may similarly deviate from the thin ideal, leading to greater 
acceptance where social comparisons are made, or possibly a sense of solidarity in the outward appearance of the body. Changing priorities, such as the life-changing event of childbearing, can also influence a woman's body image perception, as undergoing the physical changes in the body that occur during pregnancy can cause the body to deviate from the slender ideal. However, the mothers in my study commented that they were also able to adapt their perceptions of their bodies with these changes.

Age, experience, changes in the life course, and having children all were reported to varying degrees, by the participants in my study as factors that influence their inhabitancy of their own bodies. In addition to these elements, various other sociocultural impacts and influences exist, and participants reported that they enact strategies to negotiate, resolve, or interpret their bodies when confronted with cultural standards for beauty and bodily appearance, and particularly those that are disseminated through thin ideal depictions of the female body in the media.

Strategies of Body Image Resiliency

Throughout the course of the in-depth interviews, one strong emergent theoretical category that arose was the various ways in which participants mediate the impacts and influences that a variety of factors in their lives have upon their body image perceptions, which affect their self-perceptions in both positive and negative ways. Additionally, the women in this study elaborated upon the different manners by which they can better achieve or maintain a more positive body image. Some of these strategies echoed the tripartite model of influence whereby factors such as family, peers, and the media can have a significant impact on how a woman views and interprets her own body (Shroff and Thompson 2005). The strategies of body image resiliency that working class women 
who participated in my study reported echo those found in previous studies of middle class women. Furthermore, the participants in my study expressed a similar consciousness of resistance and body image resilience as middle class women have, which is perhaps a socialized response to media depictions of the female body. Working class women report similar attitudes and strategies, and by so doing, class background did not emerge in this study as an important mediating factor influencing body image interpretations or the resultant responses.

Various themes regarding the influences and impacts on body image also arose during the interview process. One strategy that some participants mentioned was that providing positive support to friends and family members experiencing negative body image issues also helped the participants to feel better about their own bodies. Positive reinforcement of one's body from a partner or significant other was also important, as was the ability for participants to engage in practices that enabled them to emphasize their femininity, such as taking more time to improve their appearance and wearing clothing that made them feel more confident. Positive self-reinforcement, such as having realistic goals and expectations for one's body and its abilities, focusing on health rather than appearance, and ignoring, avoiding, or distancing oneself from the media also proved to be useful strategies in maintaining a positive body image.

Body image impacts from family members. A major component of the tripartite model, family influence, can have significant impacts on how a woman evaluates her own body. Family influence, in particular, can influence how an individual mediates cultural pressures, such as those in the media (Choate 2005). The findings in this study echo findings by Snapp et al. (2012) in a previous study, in that "girls who receive 
affirming reactions, positive comments, and perceive a sense of approval from family about their appearance are more likely to experience positive body image as young adults" (p. 212). Some participants in this study noted the markedly negative impacts of harsh comments and critiques of their bodily appearances, and detailed the devaluation of their own self-acceptance of their bodies in response to these experiences. Many of the experiences these women recalled occurred during their childhoods. One woman mentioned, "My mom was an extremely harsh person. She was...very skinny...but she also had a jealousy problem. She was really hard on me and my sisters....So we dressed in baggy clothes, and just never thought very positively of ourselves because of it." Another participant had a similar experience in her childhood, whereby she was teased by family members. She commented,

My brother and my older step-sister made fun of me for being chunky when I was younger, probably though like fifth grade.....My brother and my step-sister were both really athletic, and I could not care less about sports or running around. I was just happy to sit and draw pictures and look at things, and so I got called chubby a lot.....My brother and my sister and I were all kind of raised by our aunt and our uncle and our grandma. And they put a lot of stress on how we looked, too.

While the reported body-shaming comments that participants shared had a distinctly negative impact on body image overall, other participants were also able to elaborate on their individual experiences regarding more positive commentaries from family members. These messages, whether positive or negative, are often instilled early in a young girl's developmental years, and can have an impact on how she interprets herself in relation to her body throughout the rest of her life. One of the participants, a thirty-five-year-old woman, made a particularly salient comment about the impacts that these messages can have on an individual. She reported "I think that a woman's 
upbringing does have a lot to do with it. If they're encouraged to just be themselves, to embrace the person that they are, I think that tends to go far. I think they tend to carry that confidence more so into their adulthood."

The majority of interviewees who mentioned experiencing positive influences detailed that the messages they received overall were about accepting oneself, and sometimes this self-acceptance was to be undertaken without regard for one's appearance. Additionally, the message instilled that many participants reported was that they should not be judged based on their looks alone, in a similar vein to how they should not judge others on appearance-based criteria. One participant commented,

When I was a little girl we were watching the Miss America pageant, it wasn't like [my parents] were saying to me, "Oh, you have to look like this." I kind of came up with that on my own, that that's the idea of quote "beauty...." They've taught me from a very young age not to judge people based on how they look, everything from the size of clothes they wear to the color of skin to what style of clothing they wear.

This particular participant recognized the broader societal standards for beauty as emulated by the contestants in the Miss America pageant, but drew a distinction between those images of beauty that she encountered and the more supportive messages she received from her family.

Another familial thread that surfaced during the interviews in regard to how individuals view themselves and their bodies was the theme of self-acceptance. One participant illustrated this point:

My family always said, “Be who you are.” My mom's advice was don't wear a lot of makeup because if you want someone to see you as your true self and without your makeup on, you're gonna wanna make sure that that you don't wear a lot of makeup. Because then you feel like you have to wear makeup all the time in order to adhere to what people think you look like, I guess. Yeah, mostly it was "Be 
yourself. Be who you are." Which I think that I pretty much am. I don't really conform. I try not to.

Here, interestingly, the participant notes that her mother had instructed her to resist certain cultural expectations regarding how women should appear, exemplified by the application of makeup. Her mother instructed her not to wear makeup because it could potentially misrepresent the participant's actual beauty, and this implies that the participant's mother valued the notion that a woman should be true to her own beauty. Overall, a thematic arch throughout the interviews was the advice to be oneself, and several participants repeated the refrain: "Be who you are."

Providing positive support to others. Many of the participants in this interview process were able to speak about the negative experiences with body image that friends, family members, and other individuals in their lives had encountered. An important concept in light of these recollections was the precedence that the participants expressed in providing positive support to other women who were experiencing negative body image issues. In many ways, serving as a supportive element in others' lives enabled participants to better recognize their own evaluations of their bodies, and contribute to fostering a more positive sense of self-acceptance. Previous research has found that "resilience may emerge for women who can first acknowledge contradictory cultural expectations and, rather than internalizing their feelings, address these conflicts directly within the context of supportive relationships" (Choate 2005:325). While discussing her little sister's body image conflicts, one participant commented,

One thing I tell her is "You know, this is your body. It gets you to where you need to be. It does the things that you need it to do. And it's beautiful for what it is. It's different than everybody else's body...." My body tells a story, and everybody else's bodies, they all tell stories....My sister's body, she's got stretch marks, and 
those tell the story of when she was in high school and was at her heaviest. And they'll never go away. She'll always have those, but that was where she was. And so she needs to embrace it as her, who she is.

During the interview process, another woman revealed a very poignant piece of advice that she had given to a friend:

My best friend has been overweight for so long and we have had conversations where if somebody had called her fat or way worse than that...I was there to comfort her and just let her know that beauty isn't about being whatever size they say you should be....She's about the most beautiful person I've ever seen in my life. She's just gorgeous. She just happened to be overweight, and so I've often... had to say, "It's not about what people think you should look like. And it's not about even what you look like; it's about what you're doing to make yourself healthier."

Self-acceptance and seeking out support emerged as being very powerful protective factors when women are confronted with body image issues. Many of the participants expressed that there is an importance to valuing oneself, and to remind friends and family members who struggle with these issues of their own uniqueness. Rather than emphasizing conformity to a rigid set of standards for female beauty, participants articulated the significance of assigning worth to one's own individuality, and cherishing the differences in people's bodies, rather than lamenting these differences as flaws. When asked about what strategies other women could implement to feel better about their bodies, one participant stated, “Just remember that everybody's different. You don't have to look like the girls in the magazines, you don't have to look like your neighbor or your best friend. That you're yourself, and your body's gonna be different than anybody else in the world."

Participants who discussed the ways in which they were able to positively support other women in their lives regarding body image also discussed the importance of relying 
upon one another for reassurance and motivation. Each of the participants in this study recognized the intrinsic benefits that can be conferred though living a certain lifestyle that includes eating well and engaging in some sort of physical activity. Some of the women reported that health-enhancing behaviors could be beneficial to their friends and family members who were struggling with body image issues, and offered a buddy system approach in helping these individuals to achieve a more positive body image overall. A twenty-eight-year-old mother described an instance of a close friend who had recently gained weight after a break-up:

She's gained a little bit of weight and she's not happy about it, so her jeans are fittin' a little bit different, and a lot of that is 'cause of the breakup she had. So for her, she keeps sayin', "Ah, I need to go back to the gym." And I'm like "Oh, you look fine the way you are, but if you want help, I'll go with you." So it's the buddy system. Encourage and enforce.

Here, the participant indicates the importance of supporting a friend who is having difficulties in maintaining a positive body image. She also iterates the value of what she calls "the buddy system," indicating that an encouraging and reassuring environment can be a worthwhile and positive endeavor.

Positive reinforcement from a partner or significant other. In the interviews, women were asked if their partners or significant others had influenced they ways in which they thought about their bodies. Of the women who were married or had boyfriends, all of them commented that their body image benefitted from hearing positive comments and receiving compliments about the way their bodies look. Women whose partners demonstrated an acceptance of their bodies were more likely to report positive acceptance of their own bodies, due in part to this supportive environment fostered by their partner. A previous study on this issue found that "while a woman's weight has the 
greatest impact on her body dissatisfaction, these results suggest that her spouse's perception, evaluation, and comments have a significant impact on her satisfaction or dissatisfaction with her body" (Pole et al. 2004:276). One woman, aged thirty-five, commented that her boyfriend positively enforces messages about her bodily appearance. She stated, "My boyfriend, he likes me the way I am, and he always tells me that. He's like "I don't want you to be super skinny, and I don't want you to feel like you have to look that way." He's very, very good about that.” Another woman, a twenty-six-year-old married mother of one with two step children commented about her husband's supportiveness. She said, "He'll say that I'm beautiful. He tells me I'm beautiful and that it wouldn't matter if I weighed 300 pounds, that he would still love me."

Other participants who identified themselves to be above their ideal weights also commented about the positive influences of their partners and significant others. Many of the participants mentioned that in the course of their relationships with their partners, their weight had fluctuated to varying degrees. In these instances, the participants reported that their partners were still very supportive, and reassured the participants that their bodies were still beautiful. When asked about how her fiancé influenced the way she thought about her body, one participant mentioned,

Absolutely, in a very positive way. When him and I first got together, I weighed about 40 pounds less than I do now, and he has made it very apparent that he appreciates the way I look. He enjoys the way I look. And he tells me I'm beautiful on a daily basis.

Another participant with a similar experience of weight gain since the beginning of her relationship stated,

Yeah, I mean, he says all the time that he thinks I'm amazing, like I have the body that he is looking for. He is like "No matter what, I think you're sexy," so, and 
that's nice, 'cause I've gained weight since we first met....He's never said, "Well, you really should lose a couple...." He always makes me feel good about myself.

This indicates that spousal or partner support is an important component of how a woman inhabits her own body. Participants reported that they felt better about themselves when their partners had reassured them about their bodies as beautiful, desirable, and aesthetically appealing.

Women in this study also mentioned the desire to look good for their partners, and this was an additional factor that emerged throughout the interviews as contributing to having a more positive body image overall. One interviewee, a married twenty-nine-yearold stay-at-home mom, commented, "I mean, he married me at my heaviest. If that's not love, I don't know what is. Cryin' out loud, I wanna look good for him, too. Call it vain, but shoot, I'd like to look good for my husband.” Interestingly, a theme that arose regarding this subject matter was that while the participants' desire to look good for their partners was somewhat extrinsically motivated, their partners did not force the issue of weight loss. In fact, none of the participants mentioned that their current romantic partners had commented that they should lose weight or have bodies that look a certain way or adhere to a particular aesthetic ideal. Instead, a more holistic approach was reported by participants in regard to their partners' appreciation for the participants as beautiful individuals overall, including the appearance of their bodies. One woman commented,

My fiancé, he really supports me. We were just having a conversation about it the other day when he said, "You know, I just want you to lose weight for you.....Not for me, or for anybody else...." But you know, he told me, "I like a woman with curves. You know, big boobs and hips, and you know, you've got about the most perfect body type." 
Positive feedback from one's partner had a motivating effect on self-perception, as one participant shared in her interview,

My husband helps, reminds me all the time of how he thinks I'm beautiful...he tells me that a lot. I think that that helps tremendously in how that makes me feel and how that makes me want to always feel that way and look that way and to just do the best I can every day.

As many of the participants I interviewed were mothers, wives or girlfriends, held full- or part-time jobs, and were various combinations of these roles, the theme of keeping oneself as a priority underscored a lot of the discussion, particularly in relation to the demands that many of the women face in their daily lives. Many of the interviewees commented that taking time to focus on themselves was an important element in maintaining a positive body image.

One participant, in particular, who recognized the strong positive impacts of healthy diet and lifestyle, detailed how she and her partner would keep each other accountable for exercising at the gym. She said,

I think that working out with somebody, first of all you feel more accountability. ...I'll ask him [my boyfriend] "Do you want to work out today?" kind of hoping that he doesn't, and he's like "Okay, let's go," ... and vice versa.... So I think you have a tendency to encourage one another, especially if one person isn't feeling up to it, then afterwards you feel great. You're happy that you did it. I think that's one of the biggest thing is that motivation that you feel when you're working out with somebody.

Here, both the participant and her partner place a great value on the benefits of being physically fit, and they engage this concept in practice by accompanying one another to the gym. In this way, the participant's significant other demonstrates both his support of her body and of her health, and the participant mentions that exercise itself has a lot of positive impacts as well. Another participant also mentioned the joint motivation to 
exercise that occurs in her relationship:

My fiancé and I both...we put on the weight together. Everybody calls it the 'Love Weight,' you know, you're happy and you go out and eat and drink and celebrate and all these things. And then we had some really extreme and stressful situations in our life. We lost the house, you know, in the fire, so all those kind of play a part. But we both know the importance of exercise and diet....We try to work out, go to the gym, do a solid hour of hardcore at least two or three times a week. And then we do things like we take our dogs for walks, or we might do yoga or pilates at home....But we're very aware of the positive effects of exercise.

The participant here demonstrates her awareness of how exercise can have a positive impact in her life, and also indicates that support of her significant other is another influence in her life that encourages her to have a more positive outlook toward her own body.

Practicing femininity. The act of taking care of one's self can have a positive impact overall on how a woman views herself and her body. Many of the participants in the interview process mentioned dressing a certain way or dedicating more time to their appearance as a route to feeling better about themselves. To some extent, these practices are actually a manifestation of internalized gender norms and expectations for appearance. To another extent, the practice of "doing femininity," as detailed by Dorothy Smith (1990), can be an important contributing factor leading to a more positive interpretation of the self. One woman commented,

I think that there's a huge difference in what we wear and what we decide to put on in the morning, whether we choose to take care of ourselves or whether we choose to lounge around in PJs all day. I feel like there's a huge difference in how it makes us feel as women. I think that for the most part, women feel better when we look nice and we wear something cute or we wear something that we like, when we put some time into ourselves. And just that little bit of extra time I think goes a long way in a girl's heart during the day.... You start the day off like that, you feel better about yourself. 
Another interviewee also briefly discussed the notion of engaging in practices to enhance her feminine beauty, 'Like last night, I got all girl, 'girlyfied' is how I called it, the makeup, and the hair, and I'm like, 'Yeah, I can be a girl. I got this."'

The theme of feeling feminine as a pathway to greater self-acceptance and empowerment was echoed in several other participants' experiences. While again, these practices may adhere to culturally-prescribed standards of feminine beauty, emulating some of these standards can also lead women to evaluate their bodies more positively. A concurrent thematic element that arose during the interview process was the inverse notion of hiding one's femininity, such as wearing large T-shirts. These experiences were reported by participants to be negative overall, while the experience of practicing femininity was described as positive. One participant mentioned,

I'd say my weight loss has made me wanna dress nicer, 'cause I used to be a big Tshirt and jeans girl, 'cause T-shirts hid everything. And now I'm discovering that I like girly clothes....I'd say that it is nice to dress up....And I don't know, but there's somethin' about walkin' around in heels that makes you feel damn important....I don't ever really wear heels, but when I do, it's like, "Yes! I have heels on. I am conquering the day!”

Another interviewee stated,

I was a tomboy when I was a kid because I was kind of ashamed of my body, and I kinda grew up into a grown-up tomboy, and so it's been a bit of a struggle for me to just figure out how to be, how to dress like somebody in her late twenties....I gravitate towards T-shirts and jeans because they make me feel safe. But...this is my last year in my twenties. This is probably the best my body is gonna be. I'm gonna be getting older. So...I bought a bunch of sun dresses last year. And I'll admit, I do feel good when I have my sun dresses on. They're soft, and it's cotton, and it's breezy, and I'm comfortable, and I feel like a girl.

Here, the participant recognizes the value of her self-worth in feeling womanly, or as she put it, "like a girl." She contrasts her experiences now with those of her youth when she struggled with body shame and issues regarding her appearance. The participant 
comments that she has reconciled her body to a degree by practicing femininity such as wearing dresses to embrace her womanliness.

Positive self-reinforcement. One motif that emerged in discussions with participants about how women can engage in having a more positive body image overall was the idea of positive self-reinforcement. The idea of treating oneself without judgment or critique became an important theme for some of the participants as the interviews progressed. One participant put the idea of positive self-reinforcement into the context of no longer striving to have an ideal body. She mentioned,

And I try to think, "Well, this is what I look like. This is how I am. This is just the way it's gonna be." I'm not going to be able to change it right off the bat, you know....I think the biggest thing that women should concentrate on before they try to better their actual looks is better their self-confidence and their love for themselves. I think that's the biggest issue, I really do, with a lot of women. If you don't love yourself, you're not gonna ever. It doesn't matter how skinny you are.

The practice of self-acceptance and self-love are important to having a more positive body image. Here, the participant comments that women who do not love themselves as they are will encounter a difficult time of loving and accepting themselves even if they improve upon their physical appearances. Because this self-acceptance is integral to having a positive body image, putting these concepts into practice in the present can help to alleviate some of the detrimental impacts a woman can experience when her body does not immediately resemble the thin ideal. This echoes prior research that has found that "women who emphasize all aspects of themselves in determining self-worth are far less vulnerable to sociocultural pressures, and women are most protected from negative body image when they do not attribute excessive importance to weight and shape in determining their self-esteem" (Choate 2005:326). 
Another participant detailed her own manner of putting self-acceptance into practice. She recommends that women stand in front of a mirror and truly identify what they are seeing. She detailed that ownership of one's body is an important aspect to achieving positive results in this practice. She stated,

First and foremost, just take a really good, long look at yourself in the mirror. It's hard sometimes because it's easy to look at yourself in the mirror and zoom in on all those things that you think are wrong. I do it myself....But if you go and look at it from the point of view of "This is my body," and not everybody is gonna know that I'm that way. Just try to look at yourself from like, "This is what other people see." Sometimes you realize you're a lot prettier and a lot more acceptable than you think. It sounds silly, but like, it's true. You just have to give yourself long enough to realize, though. It's so easy to look in the mirror and get down on yourself and to walk away because you're frustrated. But if you just stand there, I think eventually you're gonna get to that point where you're like "This is me, and I accept that." And you're gonna start looking at yourself from that point of view of "This wrinkle is my wrinkle. This scar is $m y$ scar." And I think that that's a great first step, is just knowing this is your body, this is what it looks like, and that's okay.

The participant suggests that taking ownership over one's body, even one's perceived bodily flaws, can help to facilitate a greater sense of self-acceptance.

Cultivating realistic goals and expectations. An additional influence on body image outcomes was reported by participants who indicated having realistic goals and expectations for one's body can be a helpful protective strategy against negative media imagery of the thin ideal female body. Many of the participants acknowledged their own limitations in terms of the ability to change bodily appearance. Some participants cited major changes in the body during and after pregnancy as contributing factors to how their bodies currently look. Other participants also mentioned medical conditions, such as one woman who cited the placement of a metal rod in her spine as a reason against engaging in vigorous physical activity. Overall, participants demonstrated an awareness of the 
positive impacts of diet and exercise on health and overall cardiovascular fitness, but many participants expressed an implicit concern for not wanting to have unrealistic expectations for themselves.

One participant, a thirty-year-old woman, recognized that in processing the messages from the media equating a slimmer physique with a better and more beautiful body, that a one-size-fits-all approach does not universally apply. She commented, You know, I said earlier, I am 5'9' and I am curvy. If I was wearing a size zero pant, there would be a serious issue. I would be ill....I'm never going to be that thin, and I don't want to be that thin. And I think that girls sometimes aren't told that.... You don't even really acknowledge it and understand it until you're probably in your twenties....But you're like "Wait a minute, I'm never gonna look like that, so I just need to stop trying and just focus on being healthy."

She openly states that aspiring to the elusive "size zero" that is often touted by the media to be a paramount of achievement in terms of body size is a size that would not contribute to her overall health or her happiness. The participant implies that instead of attempting a standard that isn't inclusive of a variety of body types, women should focus inward on their own health.

Another participant, a twenty-six-year-old mother, recounted her own experiences in striving to attain what she considered to be the perfect weight. She stated,

You know, there was a time when I was like, I just wanna to lose a ton of weight....and I guess recently I have finally given that up. I have been researching a lot about what the media would consider plus-size, and those women are far more gorgeous than any of the tiny women. They have the curves...they're very confident.... I've given up the whole stick thin thing. But there are the times where...I want it to be.

This participant had commented previously in the interview process that she had undergone a lifestyle change that had recently resulted in her weight loss. Here, she details a time in the past when she wanted to weigh an ideal weight, followed by the 
acknowledgement of a healthier and more realistic weight that her doctors have advised her would be a good goal. Interestingly, the participant comments that she has finally given up the notion of trying to attain that lower weight, although she later mentions that there are times when she still finds herself idealizing it. In this excerpt, the participant also mentions that beauty can be found in a diverse range of body types, and this commentary contradicts the media-related messages that beauty and thinness are inextricably linked. Previous researchers have postulated that possessing a model of acceptance that celebrates diversity can actually help women to feel better about themselves, "rather than one that breeds body insecurity among those who do not conform to the slender, well-toned, mainstream cultural ideal" (Bartky 1990; Grogan 2008:79).

When questioned about her ideal body, a thirty-five-year-old woman without children stated, "I want to feel comfortable in my skin. I want to be able to look at myself and say 'Hey, this is where I want to be. I feel good."' Feeling comfortable in one's own skin emerged as an important quality that many of the participants expressed in relation to having a positive overall body image. More often than not, participants cited that selfacceptance and striving for health were more beneficial strategies to improving body image than attempting to adhere to more rigid standards of beauty and appearance. The concept of having a body that is both healthy and functional also arose as an important component of overall body image well-being. When asked to elaborate upon her ideal body type, the participant continued,

I guess that the ideal body would be that healthier...muscle tone...not too heavy, not too skinny. I think of our bodies as...if you take everything off, you just have a skeleton. That foundation is not meant to carry that much [weight]. So that's 
another thing to be careful of, too, because you don't want to get too heavy, where your body is just not meant to carry that weight. I think ideally, people should look like their skeletons are covered with nice muscle and flesh. [Laughs] I don't know how to explain it. I think muscle tone is important. Yeah, I guess that would be my ideal.

Focusing on improving one's health rather than strictly focusing efforts on improving one's appearance materialized throughout the interview process as a meaningful value that the participants held. The implication of improving one's health is that eating a well-balanced diet and engaging in regular physical activity can eventually lead to improvements in bodily appearance, but participants cautioned against focusing solely on looks alone. One participant discussed the various benefits of living a healthy lifestyle, and contrasted these benefits with the detrimental effects of being unhealthy. She said,

I think they should just be happy with being healthy. That's what I think. You know, yeah, they need to not be overweight, because that takes years off of your life....I think they should just concentrate on being healthy and not looking like somebody else, just being healthier themselves. That's what I try and concentrate on. I'm not tryin' to be stick thin, and all that.

Another point of interest that developed over the course of some of the interviews was the virtue of internal motivation for making changes in one's life. One participant detailed her knowledge of the benefits of being healthy, and also drew upon her internal motivations for working toward positive health and lifestyle goals. She stated,

I feel like what the media depicts and what society is showing us kind of is for me is less important to look like that, to be like that. I don't feel like whether or not I wanna lose weight or I want to look a certain way....I want to do it for myself, not because I need to fill a void or look like someone else because I want what they have. So in that aspect I feel like it's...less relevant in my life. I don't need that. I feel contentment, and I want to better myself, and lose the baby weight, and I want to be healthy....But that's all for myself. So I don't look at the media and feel like I need that, you know? 
Here, the participant mentions that she values health and wants to work toward losing some weight, but that her motivations for doing so are personal, rather than influenced by external sources such as the media. She recognizes that these media overall are less relevant in her life, and that she is less interested in trying to look a certain way.

\section{Disregarding thin ideal media imagery and media messages about beauty.}

Throughout the interview process, the media's messages about beauty and standards for the appearance of the female body were discussed at length. A major theme that came to light during some of these interviews was the notion that woman can make the active choice not to engage with the media, to limit one's exposure to such negative imagery as the thin ideal, and to disregard the media's messages overall about beauty. Though many of the participants mentioned that it would be an unrealistic expectation for people to try to avoid the media altogether, one protective strategy that participants detailed was the active resistance to the deeper level of media engagement that typically results in internalization of such messages.

While, as previously mentioned, avoidance of the media altogether is not an allencompassing strategy for fully resisting the influence of the media, it can be a very helpful component to negating some of the harmful effects that thin ideal media imagery of the female body has been shown to have. When asked about how women can resist the thin ideal, one participant responded,

I think just getting away from the media. You really gotta stop watching television, stop. It's really hard not to get away from the thin ideal [unless] that is something that you do all day long. You need to get out, see people, socialize, with the right people, not the wrong people, not the people that are gonna put you down. Get them outta the way. 
As evidenced by this quote, other strategies for circumventing the thin ideal can include becoming more involved in other areas of one's life, such as becoming more active in extracurricular and social activities.

When asked whether there were people in her life who had helped her to resist the media messages about bodily appearance, one twenty-seven-year-old woman mentioned a close friend of hers. The participant stated, "We're like, anti-media. We don't really pay attention. The most we pick up is standing in Walmart at the checkout aisle. That's pretty much where we get what's happening in the media, because we don't really pay attention." Many of the participants who shared a similar sentiment did so while expressing a lack of care or concern for what was happening in the media in this regard, but they also expressed that the media can be a harmful influence when it comes to body image. Another participant stated, “I just don't care....I don't trust 'em, I guess. So...maybe it comes...subconsciously from that...I just stay away from 'em, that whole media bias. 'What we show you is what we think you should know, not necessarily what is true, but what we think you should know." Here, the participant openly identifies that the media are a biased force and that the media also have the power to bend or warp the truth. When viewed in the context of how women's bodies are portrayed in thin ideal media depictions, what this suggests is that the media have the ability to make deliberate decisions about what consumers and laypeople are exposed to.

Overall, a variety of factors that influence and impact body image emerged during the interview process undertaken during the research for this study. Participants reported that body image was affected by comments, critiques, and positive compliments from family members. Providing positive body image support to others was also a factor that 
enabled some participants to have better body image resiliency. In addition, positive reinforcement from a partner, practicing femininity, and undertaking steps to ensure positive self-reinforcement were also beneficial practices, as were developing more realistic health goals and not internalizing media messages regarding standards for female beauty.

\section{DISCUSSION}

A central theme in this study is the issue of whether or not class is an integral factor in relation to how working class women view, interpret, and understand their bodies in juxtaposition to the thin ideal media depictions of the female body they confront. The findings in my study indicate that class is not an influential factor upon which working class women draw to frame their understanding of their bodies in relation to these media depictions. This study contributes to the sociological literature by investigating an understudied population in regard to body image perceptions and the mass media. The working class women included in my study reported enacting similar resistance and body image resilience strategies as do middle class women studied in previous literature in response to the negative impacts of the thin ideal media images of the female body. This finding specifically addresses a gap in the literature because working class women had not previously been examined to this degree regarding the subject matter of class perceptions, body image, and media depictions of the female bodily form.

In sociological discourse, there exists a long-held assumption that social class placement is a strong indicator of life chances, attitudes, and lifestyle choices (Grusky and Weeden 2008). However, more recent sociological literature tempers the notion of 
social class with the concept of intersectionality, framing broad-based issues such as the concepts of gender, body image dissatisfaction, the media, and social class as constructs that may act upon individual agency in an interlocking manner, rather than singling out one prevailing factor as most influential or important (Davis 2008). Some sociological researchers have also focused on the issue of identity as a prominent indicator of how individuals relate to the world around them and place themselves within it (Crane 2000; Davis 2008). Identity is a force that can act upon individual agency, tempering issues of class, gender, and other sociocultural forces in a variety of manners that intersect, as is the case with the concept of intersectionality.

In previous studies on body image, researchers have often framed the concept of class in terms of educational attainment. Some previous studies have uncovered that correlations exist between fewer years of formal education and higher levels of overweight and obesity, and that individuals with more years of educational attainment tend to have lower levels of overweight or obesity (Molarius et al. 2000). In a study regarding the issues of educational attainment, body image, and the media, McLaren and Kuh (2004) stated that "education appears to be the key status variable contributing to body dissatisfaction. Education may have the effect of increasing women's awareness of news and media, in which women are often portrayed in a way that emphasizes their appearance" (p. 1583). In response to this finding, it is important to note that prior literature has told us little about how working class women, without the benefit of a college education, respond to media depictions of the thin, idealized body. It follows from the research conducted by McLaren and Kuh (2004) that working class women without the benefit of a university education would differ significantly in their responses 
to media depictions of a thin idealized female body from their more highly educated middle class counterparts. To extrapolate from the findings of this research, it would seem as though working class women lacking in formal education at the university level may be less educated about the power of advertising and the media in affecting their own body image dissatisfaction (McLaren and Kuh 2004). However, my study found that educational attainment did not significantly bear on how working class women view and interpret their bodies, and that despite lacking formal degrees at the university level, they have become educated elsewhere about issues of body image and the media.

My study was focused on the subjective perspectives associated with social class, and whether or not working class women differ from middle class women in their inhabitance and interpretations of their bodies by drawing upon class-based interpretations. While objective effects of class certainly come into play to influence the resources, time, and opportunities available to the women included in my study, social class did not emerge as a particularly salient frame through which the working class women in my study interpreted meanings in relation to the media or their bodies. When compared to previous studies of middle class women, the working class women in my study reported similar interpretations of their bodies in light of these media images, as well as the courses of action they undertake to ensure and maintain body image resiliency. In this regard, my findings suggest that social class does not appear to be a key influential factor in how either working class women or middle class respond to media images of a thin ideal female form with regard to their own bodies. Because the working class women in my study reported having similar views on the effects of the mass media and similar perceptions of their own bodies within this context to findings from the 
research literature detailing studies of middle class women, this indicates that body image constructs may be a contextual matter. Rather than an issue of social class, body image constructs may perhaps be framed by other issues, such as exposure to media commentary about negative impacts of the thin ideal through body acceptance campaigns, women's changing roles through the life course, changing priorities in terms of age and experience, and, perhaps, referent peer groups.

A deeper lens through which the issues of gender, body image dissatisfaction, the media, and social class may be viewed is the concept of intersectionality. Kathy Davis (2008) comments that intersectionality is suited to the task of exploring "how categories of race, class and gender are intertwined and mutually constitutive, giving centrality to questions like how race is 'gendered' and how gender is 'racialized,' and how both are linked to the continuities and transformations of social class" (p. 71). As the concept of intersectionality and the findings from my study suggest, the issue of body image constructions in relation to the mass media is far more complex than a simplistic and direct relationship between social class and body image. While issues like social class placement and educational attainment are important explanatory factors in many contexts, they were not found in my study to be particularly resonant issues through which working class women view or interpret their own bodies. Instead, it is likelier that various channels of the media, such as body acceptance campaigns, have given the participants in my study a background in how to think critically about body image and the media and a foundation upon which they have constructed their own strategies of resistance to ensure body image resiliency. 
Whereas the participants in my study did not report social class placement as a powerful lens through which they shape and moderate their interpretations, the working class women in my study reported various other mechanisms through which they mitigate the differences between their bodies and the thin idealized bodies they see in the media. By virtue of some mechanism other than formal education at the university level, the working class women I interviewed possessed a critical awareness of the media, and were able to cite the manipulative practices where they perceived them. Age and experience, such as an individual's changing values as she ages or has children, were also given as important factors in how these women perceived their own bodies. The working class women in my study had also devised resistance strategies to maintain body image resiliency, like their middle class female counterparts in previous studies. These strategies include supportiveness from family members, providing support to others, receiving positive messages from a partner or significant other, undertaking acts of femininity to feel better about one's appearance, positively reinforcing one's self by possessing realistic goals and expectations for body size and capabilities, as well as disregarding the negative media messages that equate thinness with goodness and beauty in women.

Further research is needed to explore the issue of social class and its relation to body image interpretations, with regard to the media depictions of the female body that working class women may encounter. There is a need for greater understanding of how working class women may experience and interpret their bodies in ways that differ from middle class women. An investigation into any racial or ethnic differences, in conjunction with the variable of social class, is another aspect of this issue that yet remains 
unexplored in this context. Additionally, it would be interesting to explore in greater depth how the media itself may be providing working class women with a knowledge base and educational construct regarding the framing of these issues. 


\section{CHAPTER II}

\section{AN EXAMINATION OF RESEARCH INTERESTS, METHODOLOGICAL ISSUES, AND ETHICAL CONCERNS}

\section{RESEARCH INTERESTS}

My interest in the subject matter of body image and the media is a lifelong culmination of various sociocultural influences in my life. From an early age, I engaged in gymnastics, a physically demanding and competitive sport that orients spectator focus to the observation and critique of the body and its ability to execute precise movements. I have a history of participating in athletic activities in my own life, and in conjunction with a decade of participating in gymnastics, I then engaged in cheerleading, dance, as well as yoga, Pilates, jogging, and other forms of physical exercise throughout my adolescence and adulthood. In my formative years, I also cultivated a deep interest in fashion design by teaching myself how to sew, and eventually receiving a sewing machine as a gift. This culminated into a foray into fashion design school at the college level, whereby I gained exposure to the more intricate nuances of the fashion industry, with a focus on the body aesthetic as a medium through which products could be attractively displayed and marketed for profit. When I first began my sociological training, I sought a way to combine my interest in the body as a site through which cultivation of health and overall cardiovascular fitness could be achieved and the concept 
of the body as an aesthetic vessel through which social constructs surrounding identity, value systems, and appearance can be interpreted.

My exposure to thin ideal media imagery throughout my life, and my educational training regarding the critical interpretation of these images, was also an integral component to the eventual culmination of this research interest. I gained an awareness of photograph manipulation techniques such as airbrushing, Photoshopping, as well as a broader knowledge of the skilled designers, makeup artists, and hair dressers whose expertise contributes to the idealized depictions of bodies that are predominantly displayed in the media and in advertising. I was also conscious of the extant research surrounding the issue of the use of such imagery in relation to gender, and the particularly detrimental effects of the thin ideal female body as portrayed by the media to the female consumers of such imagery.

\section{METHODOLOGICAL ISSUES}

A major methodological issue that I faced while conducting this research was the recruitment of participants who fit the criteria for inclusion in the study. These criteria included being female, between the ages of 25 to 35 , as well as individuals who did not hold bachelor's degrees (or higher), and whose parents did not hold bachelor's degrees (or higher). Individuals who had obtained higher educational training in trade schools or community college settings were included in the study. In regard to my own class standing and educational attainment, I realized that I did not have as readily-accessible connections to women who fit this description. I decided to use a hybrid approach of convenience sampling and snowball sampling in order to obtain enough participants. One manner by which I was able to find participants was by asking peers, professors, and 
family members whether they knew anyone who fit my criteria, and then obtaining the contact information for that individual. Another manner by which I was able to find participants was to interview people I knew who already fit these criteria, although these participants were few in number. Through this process, I then requested that the participant recommend to me a friend who fit my criteria, and in addition to giving me her contact information, I requested that the participant speak personally with her friend and inform that person of my study from their own perspective and experience with participation. I was able to interview many of these second-connection women for inclusion in my study. However, when these participants were asked to recommend someone, there were greater levels of hesitancy, and I was not able to interview any thirdconnection individuals.

A second major issue I encountered in conducting this study was the issue of doing in-person interviews. Because many of the participants had jobs, and due to the fact that some were married, had children, and often were dealing with multiple obligations, it was very difficult to set up in-person interviews for each of the interviews I conducted. Furthermore, conducting in-person interviews constrained me geographically, and was additionally limiting due to my own time-based obligations and financial constraints. For these reasons, it was more prudent to also conduct the in-depth audio-recorded interviews by phone, which freed up many of these time and finance-based constraints, as well as broadened my geographic scope for participant inclusion. All of the participants in the study resided in the Midwestern states.

A third confounding factor in conducting research was the issue of setting up interviews in regard to time. Of the women I knew personally, it was relatively 
uncomplicated to schedule a time to meet or talk on the phone. However, for secondconnection women whom I did not know personally, it often took several weeks to get in touch with the participant, explain the nature of my research and request their participation, receive their signed informed consent form, and conduct the actual issue. There were several instances in which potential participants were contacted, either by phone or email, and these individuals did not respond, or were unable to commit to being interviewed. In one instance, a potential participant had agreed to participate in the study, cancelled the in-person interview due to inclement weather and rescheduled for a later date, but eventually chose not to participate in the study at all.

\section{ETHICAL CONCERNS}

Throughout the process of conducting this research, I encountered various ethical concerns in relation to the study of human subjects. One of the first concerns of this nature was the manner by which I sampled my participants. Because I utilized a hybridized version of convenience sampling and snowball sampling, full confidentiality could not always be guaranteed. This was particularly poignant when I asked participants to recommend to me additional women who fit the criteria I was looking for, and who may possibly be interested in participating in my study. Although the original participants who made the suggestions were not notified as to whether the person they had recommended was included or not, the knowledge of other potential participants did not guarantee confidentiality. To mediate this issue, I informed the participants that while I would do my best to protect their confidentiality through the means available to me, such as keeping their informed consent forms in a locked cabinet, that I could not guarantee such confidentiality due to the nature of the sampling methodologies. Participants were 
made aware of the party who had specifically recommended them to me. In addition, other safeguards were put into place to protect confidentiality, such as the fact that all documents with identifying information were kept safe in locations to which only the coprincipal investigator had access, as well as the exclusion of participants' names and locations from the study in its written format. 


\section{REFERENCES}

Abell, Steven C. and Maryse H. Richards. 1996. "The Relationship Between Body Shape Satisfaction and Self-Esteem: An Investigation of Gender and Class Differences." Journal of Youth and Adolescence 35(5):691-703.

Bartky, Sandra. 1990. Femininity and Domination: Studies in the Phenomenology of Oppression. New York: Routledge.

Berg, Bruce L. 1995. Qualitative Research Methods for the Social Sciences. Needham Heights, MA: Allyn and Bacon.

Bordo, S. 2003. Unbearable Weight: Feminism, Western Culture, and the Body. Berkeley, CA: University of California Press.

Bottero, Wendy. 2004. "Class Identities and the Identity of Class." Sociology 38(5):9851003.

Bourdieu, Pierre. 1979. Distinction: A Social Critique of the Judgment of Taste. Cambridge, Massachusetts: Harvard University Press.

Bourdieu, Pierre. 1987. "What Makes a Social Class? On the Theoretical and Practical Existence of Groups.” Berkeley Journal of Sociology 32(1):1-17.

Cash, T. F., B. A. Winstead, and L. H. Janda. 1986. "Body Image Survey Report: The Great American Shape-Up.” Psychology Today 19:30-7.

Cash, T. F., and T. Pruzinsky. 2002. "Future Challenges for Body Image Theory, Research, and Clinical Practice." Pp. 509-16 in Body Images: A Handbook of Theory, Research, and Clinical Practice. New York: Guilford Press.

Chambers, Karen L. and Susan M. Alexander. 2007. "Media Literacy as an Educational Method for Addressing College Women's Body Image Issues." Education 127(4):490-6. Charmaz, Kathy. 2006. "Coding in Grounded Theory Practice." Pp. 45-71 in Constructing Grounded Theory: A Practical Guide through Qualitative Analysis. Thousand Oaks, CA: Sage Publications Ltd.

Charmaz, Kathy. 2006. "Memo-Writing.” Pp. 72-95 in Constructing Grounded Theory: A Practical Guide through Qualitative Analysis. Thousand Oaks, CA: SAGE Publications Ltd. 
Choate, Laura Hensley. 2005. "Toward a Theoretical Model of Women's Body Image Resilience." Journal of Counseling \& Development 83(3):320-30.

Conley, Dalton. 2008. "Reading Class Between the Lines (of This Volume): A Reflection on Why We Should Stick to Folk Concepts of Class." Pp. 366-58 in Social Class: How Does It Work? edited by Annette Lareau and Dalton Conley. New York, NY: Russell Sage Foundation.

Crane, Diana. 2000. Fashion and Its Social Agendas: Class, Gender, and Identity in Clothing. Chicago, IL: University of Chicago Press.

Davis, Kathy. 2008. "Intersectionality as Buzzword: A Sociology of Science Perspective on What Makes a Feminist Theory Successful." Feminist Theory 9:67-85.

Fallon, April. 1990. "Culture in the Mirror: Sociocultural Determinants of Body Image" Pp. 80-109 in Body Images: Development, Deviance, and Change, edited by T. F. Cash and T. Pruzinsky. New York, NY: Guilford Press.

Gamson, Joshua. 1994. Claims to Fame: Celebrity in Contemporary America. Berkeley CA: University of California Press, Ltd.

Goffman, Erving. 1973. The Presentation of Self in Everyday Life. Woodstock, NY: The Overlook Press.

Goffman, Erving. 1979. Gender Advertisements. New York: Harper and Row.

Greener, Joe, Flora Douglas, and Edwin van Teijlingen. 2010. "More of the Same?

Conflicting Perspectives of Obesity Causation and Intervention Amongst Overweight People, Health Professionals, and Policy Makers." Social Science and Medicine 70:1042-9.

Grogan, Sarah. 2008. Body Image. New York: Routledge.

Grogan, Sarah, and Nicola Wainwright. 1996. "Growing Up in the Culture of Slenderness.” Women's Studies International Forum 19(6): 665-73.

Grusky, David R. and Kim A. Weeden. 2008. "Are There Social Classes? A Framework for Testing Sociology's Favorite Concept” Pp. 65-89 in Social Class: How Does It Work? edited by Annette Lareau and Dalton Conley. New York: Russell Sage Foundation.

Heinberg, L.J. 1996. "Theories of Body Image: Perceptual, Developmental, and Sociocultural Factors" Pp. 24-48 in Body Image, Eating Disorders, and Obesity: An Integrative Guide for Assessment and Treatment edited by J. K. Thompson. Washington D.C.: American Psychological Association. 
Hout, Michael. 2008. "How Class Works: Objective and Subjective Aspects of Class Since the 1970s." Pp. 25-64 in Social Class: How Does It Work? edited by Annette Lareau and Dalton Conley. New York, NY: Russell Sage Foundation.

Hurd Clarke, Laura. 2002. "Older Women's Perceptions of Ideal Body Weights: The Tensions Between Health and Appearance Motivations for Weight Loss." Ageing and Society 22(06):751-73.

Jeffery, Robert W., Susan A. Adlis, and Jean L. Forster. 1991. "Prevalence of Dieting Among Working Men and Women: The Healthy Worker Project." Health Psychology 10(4):274-81.

Jeffery, R. W. and S. A. French. 1996. "Socioeconomic Status and Weight Control Practices among 20- to 45-Year Old Women." American Journal of Public Health 86(7):1005-10.

Kvale, Steiner. 2008. InterViews: Learning the Craft of Qualitative Research Interviewing. Thousand Oaks, CA: Sage Publications Inc.

Lamont, Michele. 1992. Money, Morals, and Manners: The Culture of the French and American Upper-Middle Class. Chicago, IL: The University of Chicago Press.

Lamont, Michele. 2000. The Dignity of Working Men: Morality and the Boundaries of Race, Class, and Immigration. Cambridge, MA: Harvard University Press.

Lareau, Annette. 2011. Unequal Childhoods: Class, Race, and Family Life. Berkeley, CA: The University of California Press.

McGrath, Robert J., Julie Wiggin, and Rosemary Caron. 2010. "The Relationship between Resilience and Body Image in College Women." The Internet Journal of Health 10(2).

McLaren, Lindsay, and Diana Kuh. 2004. "Women's Body Dissatisfaction, Social Class, and Social Mobility." Social Science and Medicine 58:1575-84.

Milkie, Melissa A. 2002. "Contested Images of Femininity: An Analysis of Cultural Gatekeepers' Struggles with the 'Real Girl' Critique." Gender and Society 16:83959.

Molarius, Anu, Jacob C. Seidell, Susana Sans, Jaakko Tuomilehto, and Kari Kuulasmaa. 2000. "Educational Level, Relative Body Weight, and Changes in Their Association Over 10 Years: An International Perspective from the WHO MONICA Project." American Journal of Public Health 90(08):1260-8.

Ogden, Jane and Debra Thomas. 1997. "The Role of Familial Values in Understanding the Impact of Social Class on Weight Concern." International Journal of Eating Disorders 25:273-9. 
Orbach, Susie. 1993. Hunger Strike: The Anorectic's Struggle as a Metaphor for Our Age. London: Penguin.

Pole, Michele, Janis H. Crowther, and John Schell. 2004. "Body Dissatisfaction in Married Women: The Role of Spousal Influence and Marital Communication Patterns.” Body Image 1(2004):267-78.

Rubin, Lillian B. 1992. Worlds of Pain: Life in the Working-Class Family. New York, NY: Basic Books.

Rubin, Lisa R., Carol J. Nemeroff, and Nancy Felipe Russo. 2004. "Exploring Feminist Women's Body Consciousness.” Psychology of Women Quarterly 28:27-37.

Schudson, Michael. 1984. Advertising, the Uneasy Persuasion: Its Dubious Impact on American Society. New York, N.Y.: Basic Books.

Scott, John. 1996. Stratification and Power: Structures of Class, Status and Command. Cambridge, MA: Blackwell Publishers Inc.

Shroff, Hemal, and J. Kevin Thompson. 2005. "The Tripartite Influence Model of Body Image and Eating Disturbance: A Replication with Adolescent Girls." Body Image 3:17-23.

Simmel, Georg. 1904. "Fashion." International Quarterly 10:130-55.

Smith, Dorothy. 1990. Texts, Facts, and Femininity: Exploring the Relations of Ruling. New York: Routledge.

Smolak, Linda. 2004. "Body Image in Children and Adolescents: Where Do We Go From Here?” Body Image: An International Journal of Research 1:15-28.

Snapp, Shannon, Laura Hensley-Choate, and Ehri Ryu. 2012. “A Body Image Resiliency Model for First-Year College Women.” Sex Roles 67:211-21.

Spitzer, B. L., K. A. Henderson, and M. T. Zivian. 1999. “Gender Differences in Population versus Media Body Sizes: A Comparison over Four Decades.” Sex Roles 40:545-65.

Stuber, Jenny M. 2006. "Talk of Class: The Discursive Repertoires of White Workingand Upper-Middle Class College Students." Journal of Contemporary Ethnography 35(3):285-318.

Swartz, David. 1997. Culture and Power: The Sociology of Pierre Bourdieu. Chicago, IL: University of Chicago Press. 
Thompson, J. Kevin, and Leslie J. Heinberg. 1999. "The Media's Influence on Body Image Disturbance and Eating Disorders: We've Reviled Them, Now Can We Rehabilitate Them?" Journal of Social Issues 55(2):339-53.

Tiggemann, Marika. 2004. "Body Image Across the Adult Life Span: Stability and Change.” Body Image 1:29-41.

Trottier, Kathryn, Janet Polivy, and C. Peter Herman. 2007. "Effects of Exposure to Thin and Overweight Peers: Evidence of Social Comparisons in Restrained and Unrestrained Eaters.” Journal of Social and Clinical Society 26(2):155-72.

Wang, Youfa and May A. Beydoun. 2007. "The Obesity Epidemic in the United States Gender, Age, Socioeconomic, Racial/Ethnic, and Geographic Characteristics: A Systematic Review and Meta-Regression Analysis. Epidemiologic Reviews 29:628.

Wardle, J., and L. Marsland. 1990. "Adolescent Concerns about Weight and Eating; A Social-Developmental Perspective.” Journal of Psychosomatic Research 34(4):377-91.

Williamson, David F., Jennifer Madans, Elsie Pamuk, Katharine M. Flegal, Juliette S. Kendrick, and Mary K. Serdula. 1994. "A Prospective Study of Childbearing and 10-year Weight Gain in US White Women 25 to 45 Years of Age." International Journal of Obesity 18:561-9.

Wright, Jan, Gabrielle O'Flynn, and Doune Macdonald. 2006. "Being Fit and Looking Healthy: Young Women's and Men's Constructions of Health and Fitness." Sex Roles 54(9-10):707-16.

Wright, Erik Olin. 2008. "Logics of Class Analysis" Pp. 329-49 in Social Class: How Does It Work? edited by Annette Lareau and Dalton Conley. New York, NY: Russell Sage Foundation.

Wykes, Maggie and Barrie Gunter. 2005. The Media and Body Image. Thousand Oaks, CA: SAGE Publications Ltd. 


\section{APPENDIX \\ INTERVIEW GUIDE}

\section{$\underline{\text { Class Determination }}$}

How old are you?

What do you do for a living?

What is your specific job title where you work?

What did your dad do for a living when you were growing up?

When you were growing up, did your mother work outside the home?

If so, what did she do?

What is the highest level of education you have completed?

What are the highest levels of education your parents have completed?

Do you have a partner or significant other, such as a boyfriend or husband?

If yes, what does he do for a living?

If yes, what is the highest level of education he has completed?

Do you have any children?

\section{$\underline{\text { Media Questions }}$}

What kinds of media do you usually pay attention to? (e.g., TV shows, commercials, films, Internet webpages, advertisements, magazines, etc.)

Can you give specific examples?

What do you think about how women's bodies are depicted in the media images that you see?

Do you pay attention to the way women look in advertisements? 
Do you feel that these images affect you negatively or positively? Why? Do you think that there is a difference between the ways in which women are depicted in fashion magazines versus fitness magazines? How and why?

Do you think that other women's body images are affected by media images of female bodies?

How and why?

In your opinion, do the media images of women set a standard for women?

What is that standard?

Do you feel that the media accurately portrays women in terms of body size? Why?

Can you tell me about a time when you saw a depiction of women in the media that you felt most accurately portrayed your own body type?

Do you think that media images lead you to have a positive or negative outlook towards your own body? Why?

Do you think that there is variety in the sizes and shapes of women depicted in magazines or the media?

What types of body shapes do you most frequently see?

Do you think that the media can ever have a positive impact on how women view and inhabit their bodies? If so, how?

In terms of bodies you see in the media, are there any celebrities who aren't thin but whom you admire? Why or why not?

In your opinion, do you think that women compare themselves to other women? Why?

\section{$\underline{\text { Lifestyle Questions }}$}

Has your family influenced the way you think your body should look?

Has your partner or significant other (if applicable) influenced the way you think about your body?

What types of things do you think people should do to take care of their bodies?

What do you do? What don't you do? 
Can you tell me about the different things in your life that don't allow you to meet your fitness or health goals? (e.g., too busy working or taking care of kids, post-pregnancy body changes, etc.)

Was exercise or outdoor activities something your family valued when you were growing up? Why or why not? How so?

How does exercise factor into your life now?

Can you tell me about the foods you ate growing up or any food traditions that your family had?

What types of things do you eat now?

Did any of your family members diet when you were growing up?

What are your opinions on dieting?

As you were growing up, how did your mother, sister, or other female family members or relatives talk about and relate to their bodies?

Is there anything about your upbringing that has shaped the way you think about your body?

(If they answered yes to the question on page 1) Did having children influence the way you think about your body? How?

How do you think most women like yourself feel about their bodies? Why?

How would you describe your body type?

Could you please describe for me what your own ideal body would look like?

Where do you think those ideas come from? (e.g., films, models, advertisements, etc.)

Where do you think most women get their ideas about what their bodies should look like?

\section{$\underline{\text { Resistance Questions }}$}

Do you think people from different social class backgrounds have bodies that look different? Why or why not?

Do you think their bodies are supposed to look different? Why or why not? 
Do you and your friends talk about your bodies or body image?

Can you tell me about the types of things you have talked about?

Do you and your friends try to encourage each other to resist thin ideal media depictions of women in the media? How?

Have you ever heard anyone joke about the way women's bodies in the media look? What was said?

Do you ever dress a certain way to feel better about yourself and your body?

Do you have any tattoos or piercings?

If yes, can you tell me more about them? Why did you get them? How do they make you feel about yourself and your body?

Do male friends, your partner, or other men ever comment on your body or your appearance?

If so, what do they say?

Has anyone else in your life ever encouraged you to resist negative media images of women's bodies? How?

Did you receive advice about having a positive body image when you were growing up?

What messages do you wish you had received about positive body image as you were growing up? Why?

Do you feel that how people view themselves can affect the way they make decisions in life? Why or why not?

Have you ever heard any sayings that you have found helpful to have a more positive body image?

Can you talk about what helps you personally in maintaining a positive body image? Why?

If you knew someone who felt bad about her body, what message would you want to give to her?

Do you try to resist the thin ideal media depictions of women's bodies that you encounter? How do you do so? 
What strategies do you think would be useful in helping other women feel better about themselves and their bodies? Why?

\section{$\underline{\text { Conclusion }}$}

Is there anything I did not ask that you would like to share?

Is there anything else you want to tell me that you think would help me better understand these issues?

Leading up to this interview, is there anything you thought I would ask you that I didn't? 